\title{
Glucocorticoid Receptor $\beta$ Acts As a Co-activator of T-Cell Factor 4 and \\ Enhances Glioma Cell Proliferation
}

\begin{abstract}
Qian Wang ${ }^{1,2,3 \$}$, Pei-Hua Lu ${ }^{2,3,4 \$}$, Zhi-Feng Shi ${ }^{5 \$}$, Yan-Juan $\mathrm{Xu}^{6}$, Jie Xiang ${ }^{2,3}$, Yan-Xia Wang7, Ling-Xiao Deng ${ }^{8,9}$, Ping Xie ${ }^{1,2,3}$, Ying Yin ${ }^{1,2,3}$, Bin Zhang ${ }^{1,2,3}$, Hui-Jun $\mathrm{Mu}^{1,2,3}$, Wei-Zhen Qiao ${ }^{1,2,3}$, Hua Cui ${ }^{10}$, Jian Zou ${ }^{1,2,3 *}$
\end{abstract}

1. Department of Clinical Laboratory Science, Wuxi People's Hospital Affiliated to Nanjing Medical University, Wuxi, 214023, P.R. China;

2. Wuxi Institute of Translational Medicine, Wuxi, 214023, P.R. China;

3.Jiangsu Key laboratory of Organ Transplantation, Wuxi, 214023, P.R. China

4.Department of Medical Oncology, Wuxi People's Hospital Affiliated to Nanjing Medical University, Wuxi, 214023, P.R.China

5. Department of Neurosurgery, Huashan Hospital, Fudan University, Shanghai,200040, P.R. China

6. Molecular Biology \& Protein Engineering, XBio, Inc., Shanghai, 201318, P.R.China

${ }^{7 \cdot-T r a i n i n g ~ C e n t e r ~ o f ~ B a s i c ~ M e d i c a l ~ E x p e r i m e n t s, ~ S c h o o l ~ o f ~ M e d i c i n e, ~ S h a n g h a i ~ J i a o t o n g ~}$ University, Shanghai, 200025, P.R.China

8. Department of Anatomy and Cell Biology, Indiana University School of Medicine, Indianapolis, Indiana, 46202, United States of America

9. Spinal Cord and Brain Injury Research Group, Stark Neurosciences Research Institute, Indiana University School of Medicine, Indianapolis, Indiana,46202, United States of America

${ }^{10 .}$ Department of Neurosurgery, Renji Hospital, Shanghai Jiaotong University School of Medicine, Shanghai, 200127, P.R.China

\$ These three authors equally contribute this work

* To whom correspondence may be addressed. E-mail: zoujan@gmail.com.

Correspondence: J Zou, E-mail: zoujan@gmail.com

Running title: GR $\beta$ promotes glioma cells proliferation via interaction with TCF-4

This is the author's manuscript of the article published in final edited form as: Wang, Q., Lu, P.-H., Shi, Z.-F., Xu, Y.-J., Xiang, J., Wang, Y.-X., ... Zou, J. (2014). Glucocorticoid Receptor $\beta$ Acts as a Coactivator of T-Cell Factor 4 and Enhances Glioma Cell Proliferation. Molecular Neurobiology, 52(3), 1106-1118. http://doi.org/10.1007/s12035-014-8900-9 
Abstract We previously reported that glucocorticoid receptor $\beta$ (GR $\beta$ ) regulates injury-mediated astrocyte activation and contributes to glioma pathogenesis via modulation of $\beta$-catenin/ T-cell factor/Lymphoid enhancer factor (TCF/LEF) transcriptional activity. The aim of this study was to characterize the mechanism behind cross-talk between GR $\beta$ and $\beta$-catenin/TCF in the progression of glioma. Here, we reported that GR $\beta$ knock-down reduced U118 and Shg44 glioma cell proliferation in vitro and in vivo. Mechanistically, we found that GR $\beta$ knock-down decreased TCF/LEF transcriptional activity without affecting $\beta$-catenin/TCF complex. Both GR $\alpha$ and GR $\beta$ directly interact with TCF-4, while only GR $\beta$ is required for sustaining TCF/LEF activity under hormone-free condition. GR $\beta$ bound to the $\mathrm{N}$-terminus domain of TCF-4 its influence on Wnt signaling required both ligand binding and DNA-binding domains (LBD and DBD, respectively). GR $\beta$ and TCF-4 interaction is enough to maintain the TCF/LEF activity at a high level in the absence of $\beta$-catenin stabilization. Taken together, these results suggest a novel cross-talk between GR $\beta$ and TCF- 4 which regulates Wnt signaling and the proliferation in gliomas.

Key Words Glucocorticoid receptor $\beta$;TCF-4; Interact; TCF/LEF; Glioma; Proliferation

\section{Introduction}

Aberrant activation of the canonical Wnt signaling pathway has been linked to the formation and progression of multiple types of cancers [1]. $\beta$-catenin and TCF-4 are the core components of the canonical Wnt pathway. Upon activation, $\beta$-catenin accumulates in the nucleus, where it interacts with TCF-4 and LEF-1, to form a $\beta$-catenin/TCF-4/LEF-1 complex that allows regulation of Wnt target genes known to be important for human tumorigenesis such as c-Myc [2] and Cyclin D1 [3]. Disruption of $\beta$-catenin-TCF-4/LEF-1 complex may be an ideal potential therapeutic target for controlling tumor formation and progression [4]. Meanwhile, other co-factors such as ATF2 [5] and IGFR1 [6] can interact with TCF/LEF and activate its transcriptional activity in the absence of $\beta$-catenin stabilization. Therefore, identifying co-factors and elucidating their interaction mechanism improves the understanding of TCF/LEF involvement in cancer biology. 
The glucocorticoid receptor (GR) functions as a hormone-activated transcription factor that regulates the expression of numerous glucocorticoid responsive genes and controls multiple cellular events. The human GR gene generates two C-terminal receptor isoforms, GR $\alpha$ and GR $\beta$, by alternative splicing of exons $9 \alpha$ and $\beta$ respectively. GR $\alpha$ is transported into nucleus in the presence of hormone and binds to glucocorticoid response elements (GREs) in regulatory regions of glucocorticoid-responsive genes, attracts co-activators and influences transcription. GR $\alpha$ also interacts with other transcription factors to facilitate trans-repression or trans-activation of genes [4]. GR $\beta$ shares the same N-terminal (NTD) and DNA-binding domains (DBD) with GR $\alpha$ but possesses a unique "ligand-binding” domain (LBD). A different C-terminal region with 15 non-homologous amino acids is located in the LBD. GR $\beta$ is primarily located in the nucleus where it negatively regulates GR $\alpha$ activity. Recently, GR $\beta$ was shown to exhibit intrinsic transcriptional activity and function as a transcriptional factor via a GR $\alpha$-independent manner [5,6].

Cross-talk between GR and $\beta$-catenin-TCF/LEF has been reported in several studies, and GR $\alpha$ acts as a trans-repressor on $\beta$-catenin-TCF signaling [7-9]. While, GR $\alpha$ is predominately located in cytoplasm under hormone-free condition [10], suggesting GR $\alpha$ exerts its trans-repression on $\beta$-catenin-TCF signaling is hormone dependent. Our recent study demonstrated that GR $\beta$ enhances $\beta$-catenin-TCF signaling through negative regulation of GR $\alpha$ function in the presence of hormone [9]. Mechanically, the interplay between GR $\beta$ and $\beta$-catenin was demonstrated to be a necessary component of astrocyte reactivity through sustained Wnt $/ \beta$-catenin/TCF signaling in its dominant-negative effect on GR $\alpha$ mediated trans-repression by a GSK-3 $\beta$-independent manner. Several reports have shown that aberrant activation of $\mathrm{Wnt} / \beta$-catenin/TCF signaling is an important contributing factor in glioma development (Ref) [11-13]. Our previous finding that GR $\beta$ is predominately distributed in the nucleus and contributes to glioma pathogenesis raises the consideration that the cross-talk between GR $\beta$ and $\beta$-catenin/TCF signaling involves in the progression of glioma [9].

To investigate such a role for GR $\beta$, we established stable GR $\beta$ knock-down glioma cell line from U118MG and Shg44 glioma cells. We demonstrated that GR $\beta$ regulates glioma cell proliferation by enhancing TCF/LEF without modifying the expression or nuclear localization of $\beta$-catenin. GR $\beta$ directly interacted with TCF- 4 independently of $\beta$-catenin and regulated 
TCF/LEF activity in a GR $\alpha$-independently manner, indicating that GR $\beta$ is a co-activator for TCF/LEF and their communication plays important roles in the Wnt signaling pathway.

\section{Materials and Methods}

\section{Cell Culture}

Human glioma cell line, U118MG and Shg44, the monkey kidney cell line, COS-1, human embryonic kidney cell line, HEK293, and human breast carcinoma cell line, MDA-MB-453, were obtained from the Cell Bank of Type Culture Collection of the Chinese Academy of Sciences (Shanghai, China) and cultured in DMEM with 10\% fetal bovine serum (FBS; Invitrogen, Carlsbad, CA). The stable GR $\beta$ knockdown glioma cell cultures were derived from U118 and Shg44 cells transfected with GR $\beta$ lentiviral shRNA or a scramble vector. The lentiviral GR $\beta$ shRNA and scramble vector were purchased from Genechem. The target sequence of shRNA for GR $\beta$ was described in a previous study [9]. Cell lines $>90 \%$ purity were used in subsequent experiments. The stable GR $\beta$ knockdown cells were labeled siGR $\beta$-U118 and siGR $\beta$-Shg44. The stable scramble control cells were labeled scGR $\beta$-U118 and scGR $\beta$-Shg44.

\section{Subcutaneous implantation assay}

To establish subcutaneous xenograft models, cells ( 2 X $10^{6}$ in $100 \mu$ physiological saline) were subcutaneously injected into nude mice (BALB/c nu/nu mice, National Rodent Laboratory Animal Resources, Shanghai, China ). After 28 days, the mice were sacrificed and solid tumors were carefully harvested and tumor weight was measured immediately. All mouse experiments were approved by the animal care committee at Nanjing Medical University and were carried out in accordance with government and institutional guidelines and regulations.

\section{RNA Interference and Transfection}

The siRNA sequences targeting human TCF-4 (GeneBank NM_001243236.1) and human GR (NR3C1, GeneBank NM_001018076.1) were 
5'-GGAGCUACUGUGAAGGUUUtt-3', respectively [14,15]. Their scrambled sequences served as negative controls (NC). These siRNA sequences were synthesized by Genepharma (Shanghai, China). For transfection, cells were cultured in DMEM supplemented with $10 \%$ FBS. $12 \mathrm{~h}$ after seeding, cells were transfected with the different siRNA duplexes using X-tremeGene siRNA transfection Reagent (Roche, Mannheim, Germany) at a final concentration of $100 \mathrm{nM}$. For Western blot analysis, cell proteins were prepared at $72 \mathrm{~h}$ after transfection.

\section{Vector Construction}

The hGR $\alpha$ and hGR $\beta$ expression vectors, GFP-hGR $\alpha$ and $\mathrm{pDsRed-hGR} \beta$ used in the present study were derived from methods described in our previous study [9]. The mutants of hGR $\beta$ were PCR-amplified from the constructed wide-type (wt) GR $\beta$ plasmid and cloned into a pDsRed1-N1 vector. The TCF-4 plasmid (Myc-TCF-4) [14] was obtained from the Addgene plasmid depository (Addgene plasmids 16512). A dominant negative mutant of TCF-4 (Myc-dnTCF-4, 1-80 amino deletion mutant) was amplified from the Myc-TCF-4 plasmid.

\section{Cell Growth Assay}

The cell growth assay procedure utilized was based on MTS as described previously [16]. Briefly, for assaying the effect of gene silencing on cell growth, cells were cultured in 96-well culture plates (1000 cells/well) and transfected with TCF-4 siRNA (100 nM) or GR siRNA targeting to the common sequence of GR $\alpha$ and GR $\beta(100 \mathrm{nM})$. A scrambled sequence was used as a negative control. Cell growth was determined by quantifying viable cell number using a One Solution Cell Proliferation Assay Kit (Promega, Madison, WI) at indicated time periods ( 0 h, 24 h, $48 \mathrm{~h}$ and 72 h) after transfection. The living cell number was assessed by measuring absorbance of OD570. Each experiment was repeated six times and measurements were made in triplicate.

\section{EdU Cell Proliferation Assay}

A novel thymidine analog, 5-ethynyl-2'-deoxyuridine (EdU) was used to mark DNA synthesis in proliferating cells [17]. Briefly, the U118 and U87 stable cells were cultured on poly-lysine 
(Sigma, St. Louis, MO) coated coverslips for $24 \mathrm{~h}$ followed by an incubation of EdU (Invitrogen) for $12 \mathrm{~h}$. The cells were fixed with 4\% paraformaldehyde (PFA) and the staining procedure was followed according to the manufacturer's instructions for the Click-iT ${ }^{\circledR}$ EdU Cell Proliferation Assays kit (Invitrogen). After staining, the coverslips were mounted with Gelmout containing Hoechst 33342 (Sigma) for nuclear labeling.

\section{Colony Formation Assay}

Colony formation assay was used to measure the ability of a single cell to grow into a colony [16]. In brief, before harvesting from donor cultures, 4 randomly selected stable glioma cell lines in individual group were serum starved for $24 \mathrm{~h}$. After trypsinized to produce a single-cell suspension, the cells were diluted into 50 cells per well and seed on 6-well plate. The cultures were allowed to grow for 14 days. The number of colonies $>50$ cells was counted after Coomassie blue staining.

\section{Western Blot}

For Western blot analysis, cells were harvested and lysed in RIPA lysis buffer (Cell Signal Technology, Beverly, MA). To investigate subcellular distribution of proteins, nuclear and cytoplasmic fractions were enriched using Nuclear and Cytoplasmic Protein Extraction Kit (CoWin Bioscience, China).Western blot analysis was performed as previously reported [16]. Antibodies used included rabbit anti-Cyclin D1 (1:1000, Abcam, Cambridge, UK), rabbit anti-TCF-4 (1:1000, Abcam), rabbit anti- $\beta$-catenin (1:1000, Cell Signal Technology), mouse anti- $\beta$-actin (1:2000, Abmart, China), and mouse anti-Histone H3 (1:1000, Abmart).

\section{RT-PCR}

RT-PCR was used to confirm the TCF-4 siRNA transfection by measuring the TCF-4 mRNA level in U118 and Shg44 cell lines $48 \mathrm{~h}$ after the transfection. Total RNA isolation, reverse transcription and amplified were performed as described previously [18]. The primers for PCR were as follows: TCF-4 (fwd, 5'-CGAGGGTGATGAGAACCTGC-3'; rev, 5'-CCCATGTGATTCGATGCGT-3'); $\beta$-actin (fwd, 5'-CTCCATCCTGGCCTCGCTGT-3'; rev, 5'-GCTGTCACCTTCACCGTTCC-3'). $\beta$-actin served as a loading control. 


\section{Immunoprecipitation}

Immunoprecipitation (IP) was performed as previously described [9]. In brief, cell lysates were precipitated using Protein A/G beads (Abmart) with varying antibodies. Precipitated products were assessed by immunoblot (IB) analysis. Antibodies used in IP and IB are described in the figure legends.

\section{Immunofluorescence Staining}

Immunofluorescence (IF) procedures were performed as previously reported [15]. Briefly, cells were fixed in 4\% PFA and labeled with primary antibodies overnight. The primary antibodies used in double IF included mouse anti-TCF-4 (1:100, Millipore, Bedford, MA) and rabbit anti-GR $\beta$ (1:200, Genetex) or rabbit anti-GR $\alpha$ (1:100, Abcam). Cell nuclei were counterstained with Hoechst 33342. The primary antibodies used in triple IF included conjugated goat anti- $\beta$-catenin (1:50, Santa Cruz, CA), rabbit anti-GR $\beta$ and mouse anti-TCF-4. The following day, primary antibody was washed from the coverslips followed incubation with DyLight 405, 488 and 594-conjugated secondary antibodies. Coverslips were then washed and the staining was visualized using an Olympus IX71 microscope.

\section{TCF/LEF Transcriptional Reporter Assay}

TCF transcriptional reporter activity assessment was performed as previously described [9]. Briefly, cells were transiently transfected with a Tcf-4-responsive luciferase plasmid, pGL3-OT (Addgene plasmids 16558) or a mutant Tcf-4-responsive luciferase plasmid, pGL3-OF (Addgene plasmids 16559) for $48 \mathrm{~h}$ [19]. The pRL vector was also transfected as an internal control reporter. Luciferase activity was measured using the Dual-Glo Luciferase Assay System kit.

\section{Chromatin Immunoprecipitation (ChIP) Assay}

The cells were cross-linked with $1 \%$ formaldehyde and lysed. ChIP assays were performed according to the manufacturer's protocol (Beyotime, China) with slight modifications. Chromatin solutions were sonicated and incubated with anti-TCF-4 overnight at $4^{\circ} \mathrm{C}$. Normal 
rabbit serum was used as a negative control. An anti-RNA polymerase II antibody (Pierce, Roclford, IL) was used as a positive control. GAPDH primers (sense, 5'-tactagcggttttacgggcg-3', anti-sense, 5'-tcg aacaggaggagcagagagcga-3') were supplied by the ChIP assay kit. DNA-protein cross-links were reversed and chromatin DNA was purified and subjected to PCR analysis. The primers (sense, 5'-catgctaaattagttcttgca-3'; antisense, 5'-ctggggagaccacgagaa-3') for Cyclin D1 proximal promoter (National Center for Biotechnology Information, Genbank X59798) were used to amplify the precipitated DNA [20]. After amplification, PCR products were resolved on a 1.5\% agarose gel and visualized by ethidium bromide staining. For input control, the non-IP DNA-protein complex was performed using the same primers.

\section{Statistical Analysis}

SPSS 12.0 was applied to carry out statistical analyses. Data were presented as mean \pm SEM, and statistical analysis was carried out by analysis of variance, followed by Student's t test with a significance of $p<0.05$.

\section{Results}

\section{GRß Knock-down Impairs the Proliferation of U118 and Shg44 Glioma Cells}

Our previous study reported that GR $\beta$ regulates the reactive response of astrocytes after injury by modulating $\beta$-catenin/TCF signaling and knock-down of GR $\beta$ impaired biological characteristics of glioma cells [9]. To further investigate the significance of GR $\beta$ in glioma, in the present study we established stable U118 and Shg44 glioma cells derived from GR $\beta$ knock-down (siGR $\beta$-U118 and siGR $\beta$-Shg44) and scramble shRNA transfected (scGR $\beta$-U118 and scGR $\beta$-Shg44) U118 and Shg44 cells using lentivial shRNA vectors based on previously reported sequence $[9,21]$. No changes in cell viability and apoptosis were observed in these cells (data not shown). Similar to the previous study, GR $\beta$ knock-down resulted in a cell growth inhibition in these glioma cells (Fig. 1a,b). This effect was further demonstrated by an EdU incorporation experiment (Fig. 1c,d). GR $\beta$ knock-down also resulted in a suppression of colony formation (Fig. 1e,f). Furthermore, when transplanted into nude mice, siGR $\beta$-U118 and siGR $\beta$-Shg44 formed smaller tumors than scGR $\beta$-U118 and scGR $\beta$-Shg44 cells (Fig. 
1g).These findings support our previous results suggesting that GR $\beta$ plays a significant role in the proliferation of glioma cells.

\section{GRß Knock-down Reduces Transcriptional Activity of $\beta$-catenin/TCF in Glioma Cells}

To determine whether GR $\beta$ regulates cell growth of glioma cells through modulation of $\beta$-catenin/TCF signaling, the stable cells were transfected with a TCF/LEF reporter plasmid, pGL3-OT, to monitor $\beta$-catenin/TCF mediated transcriptional activity [19]. The activity of $\beta$-catenin/TCF was measured by the relative luciferase activity of pGL3-OT. As shown in Fig. 2a,b, GR $\beta$ knock-down resulted in a significant reduction of basal $\beta$-catenin/TCF activity in siGR $\beta$-U118 cells and siGR $\beta$-Shg44 cells. pGL3-OF, containing a mutant TCF-4 binding site, served as a negative control and did not significantly change in these cells (data not shown). Accordingly, the expression of $\beta$-catenin/TCF targeting gene, Cyclin D1 was decreased in siGRß-U118 (Fig. 2c) and siGR $\beta$-Shg44 cells (Fig. 2d). Further experiment in ChIP assay in U118 stable cells revealed a significantly reduced binding of TCF-4 to its target gene promoter, Cyclin D1 (Fig. 2e). These results suggested the possibility that GR $\beta$ regulates glioma cell proliferation by modulating $\beta$-catenin/TCF activity.

\section{GRß Regulates Glioma Cell Proliferation Independently of $\beta$-catenin-TCF-4 Complex}

The nuclear $\beta$-catenin-TCF complex plays a pivotal role in $\beta$-catenin/TCF signaling and activation of Wnt target genes [22]. We next examined whether the decreased $\beta$-catenin/TCF transcriptional activity was caused by the reduction of TCF-4 and $\beta$-catenin expression or their interaction after GR $\beta$ knock-down. As shown in Fig. 2c and d, no detectable change in TCF- 4 and $\beta$-catenin was observed in total protein of stable U118 and Shg44 cells after GR $\beta$ knock-down. In Wnt signaling pathway, nuclear $\beta$-catenin forms a complex with TCF/LEF and regulates the expression of Wnt target genes; however, immunoprecipitation (IP) experiment revealed that GR $\beta$ knock-down did not induce detectable change in $\beta$-catenin-TCF-4 interaction (Fig. 3a). Aberrant or sustained Wnt signaling has been linked to human cancers and the nuclear $\beta$-catenin-TCF complex acts as a critical aspect of the responsiveness of a cell to a specific Wnt signaling via a $\beta$-catenin responsive transcription (CRT) mechanism [22]. Triple immunostaining with $\beta$-catenin, TCF-4 and GR $\beta$ showed that 
only a small portion of $\beta$-catenin co-localized with TCF-4 in nuclei of U118 cells and Shg44 cells (Fig. 3b). As shown in the IP experiment (Fig. 3c), only a weak interaction of $\beta$-catenin and TCF-4 was observed in these two cell lines. In this experiment, HCT116 cells, a cell line with constitutively elevated levels of CRT acted as a positive reference [22]. It suggested that the CRT mediated transcription may be not a vital contributor for glioma cells growth. To test this idea, iCRT3, a Wnt signaling inhibitor which specifically inhibits CRT activity by disrupting $\beta$-catenin-TCF interaction [22] was used in the cell growth assay (Fig. 3d-f). As a positive control, the cell growth of HCT116 was significantly inhibited by the iCRT3 treatment (Fig. 3d). While, such growth inhibition was not observed in U118 and Shg44 cells (Fig. 3e,f). Meanwhile, a TCF-4 specific siRNA mediated knock-down resulted in a significant growth inhibition both in U118 cells and Shg44 cells (Fig. 3g,h), indicating TCF-4 mediated transcriptional activity is an important regulator for U118 cell growth. Therefore, these observations demonstrated that TCF- 4 has $\beta$-catenin-independent effects mediated regulation of cell growth of glioma cells and the regulation of GR $\beta$ on glioma cell proliferation is $\beta$-catenin-TCF complex independently.

\section{GRß Interacts with TCF-4 Directly by Binding with Its N- terminus}

Previous observations have provided evidences that TCF proteins have effects independent of $\beta$-catenin mediated activation of target genes [23]. As GR $\beta$ modulated TCF/LEF transcriptional activity and regulated cell growth in a CRT-independent manner in U118 and Shg44 glioma cells, we speculated a new mechanism for TCF/LEF transcriptional activity mediated by GR $\beta$ distinct from that associated with canonical Wnt signaling. We supposed that GR $\beta$ might be a transcription co-factor of TCF-4 and sustains activation of Wnt signaling. To test this hypothesis, we first investigated whether GR $\beta$ interacts with TCF-4. The immunostaining shown in Fig. 4a, as well as the triple immunostaining in Fig. 3b show that GR $\beta$ was mainly distributed in the nucleus and co-localized with TCF-4, while GR $\alpha$ was predominately expressed in cytoplasm. The IP results showed that both GR $\beta$ and GR $\alpha$ can interact with TCF-4 in U118 glioma cells. It also indicated that the amount of GR $\alpha$ interacting with TCF-4 was significantly less than that shown for GR $\beta$ (Fig. 4b). This outcome perhaps resulted from the predominately cytoplasmic distribution of GR $\alpha$, indicating no obvious effect 
of GR $\alpha$ on Wnt signaling in U118 cells was associated with its low activity under hormone-free conditions. Since our previous study demonstrated an interaction between GR and $\beta$-catenin, we performed an IP experiment to examine whether the binding of TCF-4 and GR $\beta$ or GR $\alpha$ was $\beta$-catenin-independent. The $\beta$-catenin negative MDA-MB-453 cells [24] were co-transfected with plasmids of Myc-TCF-4 and pk7-GR $\alpha$-GFP or pDsRed1-GR $\beta$ (ratio, 2:1) and cell proteins were immunoprecipitated with mouse anti-Myc antibody followed by immunoblot (IB) with rabbit anti-Myc and GFP or RFP antibodies. As shown in Fig. 4c, the two recombinant GR isoforms could interact with recombinant TCF-4 in a $\beta$-catenin-independent manner. The first 80 amino of TCF-4 has been reported to be important for TCF-4 binding its co-factors [25]. To investigate whether this domain is involved in the interaction of TCF-4 and GR $\alpha$ or GR $\beta$, we expressed pDsRed1-GR727 (mutant with the same amino acid 1-727 region of GR $\alpha$ and GR $\beta$ ) and N-terminal (1-80) deletion mutant of TCF-4 (dominate negative mutant of TCF-4, Myc-dnTCF4) in the GR-free COS-1 cell line. IP experiment showed that the deletion of N-terminal domain blocked the interaction of TCF-4 and GR (Fig. 4d). These experiments suggested that the N-terminal domain of TCF-4 contributes to its interaction with GR $\alpha$ and GR $\beta$.

\section{GRß, not GR $\alpha$ Affects the Transcriptional Activity of TCF/LEF in Glioma Cells}

Activated GR $\alpha$ stimulated by dexamethasone (Dex) can inhibit growth in glioma cells [26,27]. In addition, this inhibition was further enhanced in GR $\beta$ knock-down glioma cells (Supplementary Fig. 1a). GR $\alpha$ acts as a trans-repressor of Wnt/ $\beta$-catenin signaling, while GR $\beta$ has a negative effect on the function of GR $\alpha[4,9]$. As expected, GR $\beta$ knocking-down promoted the inhibition of GR $\alpha$ on TCF/LEF activity under Dex stimulation (Supplementary Fig. 1b). The result is consistent with our previous finding that GR $\beta$ exerts negative effect on GR $\alpha$ mediated trans-repression on Wnt signaling. To investigate whether the reduction of TCF/LEF activity after GR $\beta$ knock-down was associated with the repressive effect of GR $\alpha$

under hormone free condition, TCF/LEF transcriptional activity was examined in siGR $\beta$-U118 cells following a GR siRNA transfection which targeted a common sequence of GR $\alpha$ and GR $\beta$. No detectable change of TCF/LEF activity or Cyclin D1 expression was observed in these cells after GR knock-down (Fig. 5a,b). GR knock-down by GR siRNA 
transfection had no effect on siGR $\beta$-U118 cell proliferation (Fig. 5c). It suggested that GR $\alpha$ is not a key repressive factor on Wnt/ $\beta$-catenin signaling in siGR $\beta$-U118 cells under hormone-free conditions. Next, we investigated whether GR $\beta$ transfection could rescue the TCF/LEF transcriptional activity in siGR $\beta$-U118 cells. A ChIP assay using anti-TCF-4 antibody was performed to confirm this. The siGR $\beta$-U118 cells were transfected with pDsRed1-GR $\beta$ or pDsRed1 plasmid. As shown in the ChIP assay (Fig. 5d), the increase in GR $\beta$ enhanced the binding of TCF-4 to the Cyclin D1 promoter in GR $\beta$ knock-down cells. It also resulted in an increase of Cyclin D1 expression as shown in the Western blot assay (Fig. 5e). These results suggested that GR $\beta$ modulates TCF activity in U118 cells via a GR $\alpha$-independent mechanism.

\section{The Effects of GRß on Wnt Signaling is Dependent on the DBD and LBD Domain}

We attempted to reciprocally determine which domain of GR $\beta$ is critical for its interaction with TCF-4. For this purpose, an IP experiment was performed in HEK293 cells co-transfected with different deletions of GR $\beta$ and Myc-TCF-4 (Fig. 6a,b). The results showed that the GR $\beta$ 1-488^556-742 mutant cannot bind to TCF-4 indicating the DBD (418-488) is essential for the binding of GR $\beta$ to TCF-4 (Fig. 6b). Furthermore, to determine whether GR $\beta$ induction of Wnt-mediated transcription is dependent upon the DBD domain, we co-expressed GR $\beta$ mutants with Myc-TCF-4 in COS-1 cells. Results from a luciferase experiment with pGL3-OT/OF reporters showed that wide-type GR $\beta$ and the GR $\beta$ 418-742 mutant significantly increased Wnt1-mediated luciferase activity (Fig. 6c). This indicated that the NTD (1-418) is not critical for TCF-4 binding and transactivation of TCF/LEF. These results also demonstrated that besides the DBD, the whole LBD (488-742) including the activation functions 2 (AF2) domain is essential for transactivation of GR $\beta$. Mifepristone (RU486) acts as an antagonist of GR $\beta$ by binding the LBD of GR $\beta[4,5]$. Here we showed that although RU486 treatment resulted in a growth inhibition in U118 and Shg44 cells (Supplementary Fig. 2a,b), it did not affect TCF/LEF activity (Supplementary Fig. 3a) or the binding capacity of GR $\beta$ to TCF-4 (Supplementary Fig. 3b). It is possible that RU486 may inhibit GR $\beta$ intrinsic transcriptional activity via a TCF/LEF independent manner and the ligand-binding function of LBD does not affect the interaction of GR $\beta$ and TCF-4. 


\section{Discussion}

Wnt/ $\beta$-catenin/TCF signaling and $\beta$-catenin/TCF/LEF complex are important contributors to the development of multiple cancers including glioma $[28,13,12]$. The findings presented here revealed for the first time that GR $\beta$ serves as a co-activator for Wnt signaling potentiating glioma progression by interacting to TCF-4. By directly binding to TCF-4, GR $\beta$ sustains TCF/LEF transcriptional activity independent of $\beta$-catenin. The glucocorticoid receptor (GR) binds to GREs in the promoters of glucocorticoid responsive genes activates their transcription, and regulates activity and suppression of other transcriptional factors. The role of GR isoforms have been widely investigated and GR $\alpha$, in particular, mediates most of the known actions of GR [29]. In contrast, the functions of GR $\beta$ have been remained largely unknown. GR $\beta$ is known as a dominant negative regulator of GR $\alpha$-mediated transcriptional activity; however, previous research has demonstrated that GR $\beta$ exerts positive and negative influence on the transcriptional activity of large subsets of genes, most of which are not responsive to glucocorticoids [4]. Here we expanded the understanding of GR $\beta$ function and further uncovered a novel mechanism in the regulation of other genes' transcriptional activity (see model in Figure 7). .

Under glucocorticoid stimulation, ligand-bound GR $\alpha$ undergoes nuclear translocation and negatively regulates Wnt signaling through indirect and direct binding to $\beta$-catenin $[7,30]$. As revealed in this study, interaction between GR $\alpha$ and TCF-4 suggests that GR $\alpha$ may regulate the transcriptional activity of TCF-4 via a $\beta$-catenin-independent process. In glioma cells with low level of nuclear $\beta$-catenin, the trans-repression of GR $\alpha$ on TCF/LEF activity was further enhanced by GR $\beta$ knock-down under glucocorticoid stimulation. This introduces the possibility that the negative effect of GR $\beta$ on GR $\alpha$ in Wnt signaling is mediated through competitive binding of GR $\beta$ and GR $\alpha$ to TCF-4. This interaction occurred in nuclei and whereas GR $\alpha$ is predominately localized in cytoplasm; therefore, the negative function of GR $\alpha$ on TCF-4 is likely hormone-dependent. As a result, no increase of TCF/LEF activity was observed following GR knock-down under hormone-free condition. We propose that GR $\beta$ is an active factor in Wnt signaling in glioma cells, rather than a protein simply affiliated with GR $\alpha$. 
The nuclear $\beta$-catenin-TCF complex plays a central role in the transcription of Wnt target genes [13]. Our observation that GR $\beta$ interacted with $\beta$-catenin and TCF-4 implies that GR $\beta$ can affect $\beta$-catenin binding to TCF-4. Meanwhile, no changes in $\beta$-catenin and $\beta$-catenin-TCF-4 complex expression were observed after GR $\beta$ knock-down. This suggests that GR $\beta$ can modulate TCF/LEF activity without affecting the $\beta$-catenin-TCF complex. High Wnt/ $\beta$-catenin activity is believed to be associated with increased malignancy and adverse outcome of gliomas $[31,12,32,33]$. TCF-4 and the $\beta$-catenin-TCF-4 complex promote glioma cell growth and stemness upon Wnt signaling activation [31, 36]. While, under normal culture conditions, the minimal nuclear $\beta$-catenin distribution and $\beta$-catenin-TCF complex is not sufficient to direct growth in U118 and Shg44 cells. However, TCF-4 still emerged as a key factor which regulated growth in these cells. The newly identified function of GR $\beta$, as well as previous findings [34], indicate TCF/LEF transcriptional activity is affected by multiple factors, and not just limited by $\beta$-catenin activity. Unlike p15Rs [32], the involvement of GR $\beta$ in Wnt signaling does not appear to occur through disrupting or enhancing the interaction of $\beta$-catenin and TCF-4. The present observation that the N terminus of TCF-4, which serves as the binding site for $\beta$-catenin [35], allowed for binding to GR $\beta$ implies that GR $\beta$ may competes with inhibitory factors like p15Rs [36] and GRG5/AES [37] for binding to TCF-4. Nevertheless, these results suggest that the GR $\beta / T C F-4$ transaction complex is an additional target in Wnt signaling for inhibiting tumor development and progression. However, the present study cannot rule out the involvement of cross-talk between cytoplasmic $\beta$-catenin and GR $\alpha$ or $\beta$ without GR ligand. Our unreported data showed that siRNA targeting $\beta$-catenin resulted in inhibited growth in glioma cells, without inducing a significant decrease of TCF/LEF activity. These findings suggested that the cell growth regulation of $\beta$-catenin is not occurs independently of TCF/LEF mediated transcription $[38,39]$. The interaction of $\beta$-catenin and GR $\alpha$ or GR $\beta$ reported in our previous study indicates that the interaction of cytoplasmic $\beta$-catenin and GR $\alpha$ or GR $\beta$ may also play roles in the regulation of cell proliferation via a presently unclear mechanism [9].

Our observation that the DBD is essential for GR $\beta$ binding to TCF-4 indicated that GR $\alpha$ and GR $\beta$ share the same TCF-4 binding domain. This also implies that competitive interaction exists between GR $\alpha$ and GR $\beta$. In the absence of hormone, GR $\alpha$ is a cytoplasmic-dominant 
protein. To intensify the inhibitory activity of GR $\alpha$ on Wnt signaling, it is possible that GR interacts with TCF/LEF in a hormone-independent manner while repressing the activity of TCF/LEF as observed in the presence of hormone. Another feasible method to verify this is to introduce a recombinant nuclear-forcing DBD protein to block the GR binding site of TCF-4. Other than the DBD, the enhancement of TCF/LEF activity by GR $\beta$ required the entire LBD, suggesting the differing action in regulating Wnt signaling between GR $\alpha$ and GR $\beta$ may be due to divergence at the $728^{\text {th }}$ amino acid residue of the GR isoforms. Two AF2 domains have been mapped to the LBD of human GR $\alpha$. The AF2 domain (residues 526-556) possesses transactivation potential in the context of full-length GR $\alpha$ by recruiting co-regulators [40,30,41,42]. The C-terminal AF2 domain (residues 728-763 or 753-768) of GR $\alpha$ is responsible for hormone-dependent interaction with co-activators of the p160 family, e.g. SRC-1 $[43,44]$. The observation that the AF2 domain (residues 526-556) is essential for the modulation of GR $\beta$ on TCF/LEF suggests that different co-regulators recruited through this region lead to different action of GR isoforms. Our study demonstrated that the DBD-AF2 domain (residues 418-556) is unable to take on the action of GR $\beta$ on Wnt signaling which indicates that GR $\beta$ action is a cooperative process involving these three components. As a result of the hormone-independent action of GR $\beta$, the C-terminal domain (residues 728-742) may be a distinct functional domain that determines transaction or transrepression of GR $\beta$; however, its exact function has not been clearly defined. In addition, the observation that RU486-binding LBD did not exert inhibition on of GR $\beta$ and TCF-4 interaction and TCF/LEF activity indicated that the ligand only affects the direct modulation of GR $\beta$ on gene transcriptional activity; it does not affect transcriptional modulation of GR $\beta$ on other transcription factor activities by incorporating into the transcriptional intermediate complex.

In conclusion, the findings shown in the present study help redefine GR $\beta$ as a new nuclear positive-regulator of the Wnt signaling through TCF-4 interaction in glioma cells. This discovery extends our understanding of GR action to Wnt signaling, which reveals new questions and possibilities concerning the role and mechanistic activity of GR in cellular activities. Given the well-established roles of Wnt signaling in various cancers, we expect that our findings on the functional interaction of GR $\alpha$ and GR $\beta$ with TCF-4 will provide useful information for the development of effective therapies against glioma and related disease. 
Acknowledgments This work was supported by Natural Science Foundation of China (NFSC) grants (no.81372710 and 81000527 to Jian Zou; no. 81101801 to Peihua Lu; no. 81100547 to Jie Xiang); Natural Science Foundation of Jiangsu Province (NFSJS) grant (no. BK2010159 to Jian Zou). We thank Bert Vogelstein for having provided the pcDNA/Myc TCF4, pGL3-OT and pGL3-OF plasmids, these plasmids were obtained through the Addgene plasmid depository. The authors thank Clarity Manuscript Consultants for their language editing.

Financial Support This work was supported by Natural Science Foundation of China (NFSC) grants (no.81372710 and 81000527 to Jian Zou; no. 81101801 to Peihua Lu; no. 81100547 to Jie Xiang); Natural Science Foundation of Jiangsu Province (NFSJS) grant (no. BK2010159 to Jian Zou).

\section{Conflict of Interest None}

\section{References:}

1. Holland JD, Klaus A, Garratt AN, Birchmeier W (2013) Wnt signaling in stem and cancer stem cells. Curr Opin Cell Biol 25:254-264

2. van de Wetering M, Sancho E, Verweij C, de Lau W, Oving I, Hurlstone A, van der Horn K, Batlle E, Coudreuse D, Haramis AP, Tjon-Pon-Fong M, Moerer P, van den Born M, Soete G, Pals S, Eilers M, Medema R, Clevers H (2002) The beta-catenin/TCF-4 complex imposes a crypt progenitor phenotype on colorectal cancer cells. Cell 111:241-250

3. Barkai N, Rose MD, Wingreen NS (1998) Protease helps yeast find mating partners. Nature 396:422-423

4. Kino T, Su YA, Chrousos GP (2009) Human glucocorticoid receptor isoform beta: recent understanding of its potential implications in physiology and pathophysiology. Cell Mol Life Sci 66:3435-3448

5. Lewis-Tuffin LJ, Jewell CM, Bienstock RJ, Collins JB, Cidlowski JA (2007) Human glucocorticoid receptor beta binds RU-486 and is transcriptionally active. Mol Cell Biol 27:2266-2282

6. Kino T, Manoli I, Kelkar S, Wang Y, Su YA, Chrousos GP (2009) Glucocorticoid receptor (GR) beta has intrinsic, GRalpha-independent transcriptional activity. Biochem Biophys Res Commun 381:671-675

7. Olkku A, Mahonen A (2009) Calreticulin mediated glucocorticoid receptor export is involved in beta-catenin translocation and Wnt signalling inhibition in human osteoblastic cells. Bone 44:555-565

8. Taniguchi Y, Iwasaki Y, Tsugita M, Nishiyama M, Taguchi T, Okazaki M, Nakayama S, Kambayashi M, Hashimoto K, Terada Y (2010) Glucocorticoid receptor-beta and receptor-gamma exert dominant 
negative effect on gene repression but not on gene induction. Endocrinology 151:3204-3213

9. Yin Y, Zhang X, Li Z, Deng L, Jiao G, Zhang B, Xie P, Mu H, Qiao W, Zou J (2013) Glucocorticoid receptor beta regulates injury-mediated astrocyte activation and contributes to glioma pathogenesis via modulation of beta-catenin/TCF transcriptional activity. Neurobiol Dis 59:165-176

10. Zhang X, Clark AF, Yorio T (2008) FK506-binding protein 51 regulates nuclear transport of the glucocorticoid receptor beta and glucocorticoid responsiveness. Invest Ophthalmol Vis Sci 49:1037-1047

11. Yang C, Iyer RR, Yu AC, Yong RL, Park DM, Weil RJ, Ikejiri B, Brady RO, Lonser RR, Zhuang Z (2012) beta-Catenin signaling initiates the activation of astrocytes and its dysregulation contributes to the pathogenesis of astrocytomas. Proc Natl Acad Sci U S A 109:6963-6968

12. Zhang J, Huang K, Shi Z, Zou J, Wang Y, Jia Z, Zhang A, Han L, Yue X, Liu N, Jiang T, You Y, Pu P, Kang C (2011) High beta-catenin/Tcf-4 activity confers glioma progression via direct regulation of AKT2 gene expression. Neuro Oncol 13:600-609

13. Pu P, Zhang Z, Kang C, Jiang R, Jia Z, Wang G, Jiang H (2009) Downregulation of Wnt2 and beta-catenin by siRNA suppresses malignant glioma cell growth. Cancer Gene Ther 16:351-361

14. Comes N, Borras T (2007) Functional delivery of synthetic naked siRNA to the human trabecular meshwork in perfused organ cultures. Mol Vis 13:1363-1374

15. Forrest MP, Waite AJ, Martin-Rendon E, Blake DJ (2013) Knockdown of human TCF4 affects multiple signaling pathways involved in cell survival, epithelial to mesenchymal transition and neuronal differentiation. PLoS One 8:e73169

16. Yin Y, Sun W, Xiang J, Deng L, Zhang B, Xie P, Qiao W, Zou J, Liu C (2013) Glutamine synthetase functions as a negative growth regulator in glioma. J Neurooncol 114:59-69

17. Diermeier-Daucher S, Clarke ST, Hill D, Vollmann-Zwerenz A, Bradford JA, Brockhoff G (2009) Cell type specific applicability of 5-ethynyl-2'-deoxyuridine (EdU) for dynamic proliferation assessment in flow cytometry. Cytometry A 75:535-546

18. Zou J, Wang YX, Mu HJ, Xiang J, Wu W, Zhang B, Xie P (2011) Down-regulation of glutamine synthetase enhances migration of rat astrocytes after in vitro injury. Neurochem Int 58:404-413

19. Shih IM, Yu J, He TC, Vogelstein B, Kinzler KW (2000) The beta-catenin binding domain of adenomatous polyposis coli is sufficient for tumor suppression. Cancer Res 60:1671-1676

20. Wen W, Ding J, Sun W, Wu K, Ning B, Gong W, He G, Huang S, Ding X, Yin P, Chen L, Liu Q, Xie W, Wang H (2010) Suppression of cyclin D1 by hypoxia-inducible factor-1 via direct mechanism inhibits the proliferation and 5-fluorouracil-induced apoptosis of A549 cells. Cancer Res 70:2010-2019 21. Goleva E, Li LB, Eves PT, Strand MJ, Martin RJ, Leung DY (2006) Increased glucocorticoid receptor beta alters steroid response in glucocorticoid-insensitive asthma. Am J Respir Crit Care Med 173:607-616

22. Gonsalves FC, Klein K, Carson BB, Katz S, Ekas LA, Evans S, Nagourney R, Cardozo T, Brown AM, DasGupta R (2011) An RNAi-based chemical genetic screen identifies three small-molecule inhibitors of the Wnt/wingless signaling pathway. Proc Natl Acad Sci U S A 108:5954-5963

23. Yi F, Merrill BJ (2007) Stem cells and TCF proteins: a role for beta-catenin--independent functions. Stem Cell Rev 3:39-48

24. Kim SY, Dunn IF, Firestein R, Gupta P, Wardwell L, Repich K, Schinzel AC, Wittner B, Silver SJ, Root DE, Boehm JS, Ramaswamy S, Lander ES, Hahn WC (2010) CK1epsilon is required for breast cancers dependent on beta-catenin activity. PLoS One 5:e8979

25. Miravet S, Piedra J, Miro F, Itarte E, Garcia de Herreros A, Dunach M (2002) The transcriptional 
factor Tcf-4 contains different binding sites for beta-catenin and plakoglobin. J Biol Chem 277:1884-1891

26. Liu H, Huang X, Wang H, Shen A, Cheng C (2009) Dexamethasone inhibits proliferation and stimulates SSeCKS expression in C6 rat glioma cell line. Brain Res 1265:1-12

27. Piette C, Deprez M, Roger T, Noel A, Foidart JM, Munaut C (2009) The dexamethasone-induced inhibition of proliferation, migration, and invasion in glioma cell lines is antagonized by macrophage migration inhibitory factor (MIF) and can be enhanced by specific MIF inhibitors. J Biol Chem 284:32483-32492

28. Yue X, Lan F, Yang W, Yang Y, Han L, Zhang A, Liu J, Zeng H, Jiang T, Pu P, Kang C (2010) Interruption of beta-catenin suppresses the EGFR pathway by blocking multiple oncogenic targets in human glioma cells. Brain Res 1366:27-37

29. Maeda Y, Rachez C, Hawel L, 3rd, Byus CV, Freedman LP, Sladek FM (2002) Polyamines modulate the interaction between nuclear receptors and vitamin D receptor-interacting protein 205. Mol Endocrinol 16:1502-1510

30. Takayama S, Rogatsky I, Schwarcz LE, Darimont BD (2006) The glucocorticoid receptor represses cyclin D1 by targeting the Tcf-beta-catenin complex. J Biol Chem 281:17856-17863

31. Schule R, Dictus C, Campos B, Wan F, Felsberg J, Ahmadi R, Centner FS, Grabe N, Reifenberger G, Bermejo JL, Unterberg A, Herold-Mende C (2012) Potential canonical wnt pathway activation in high-grade astrocytomas. ScientificWorldJournal 2012:697313

32. Liu C, Tu Y, Sun X, Jiang J, Jin X, Bo X, Li Z, Bian A, Wang X, Liu D, Wang Z, Ding L (2011) Wnt/beta-Catenin pathway in human glioma: expression pattern and clinical/prognostic correlations. Clin Exp Med 11:105-112

33. Zhang N, Wei P, Gong A, Chiu WT, Lee HT, Colman H, Huang H, Xue J, Liu M, Wang Y, Sawaya R, Xie K, Yung WK, Medema RH, He X, Huang S (2011) FoxM1 promotes beta-catenin nuclear localization and controls Wnt target-gene expression and glioma tumorigenesis. Cancer Cell 20:427-442

34. Hong CF, Chou YT, Lin YS, Wu CW (2009) MAD2B, a novel TCF4-binding protein, modulates TCF4-mediated epithelial-mesenchymal transdifferentiation. J Biol Chem 284:19613-19622

35. Poy F, Lepourcelet M, Shivdasani RA, Eck MJ (2001) Structure of a human Tcf4-beta-catenin complex. Nat Struct Biol 8:1053-1057

36. Wu Y, Zhang Y, Zhang H, Yang X, Wang Y, Ren F, Liu H, Zhai Y, Jia B, Yu J, Chang Z (2010) p15RS attenuates Wnt/\{beta\}-catenin signaling by disrupting \{beta\}-catenin.TCF4 Interaction. J Biol Chem 285:34621-34631

37. Costa AM, Pereira-Castro I, Ricardo E, Spencer F, Fisher S, da Costa LT (2013) GRG5/AES interacts with T-cell factor 4 (TCF4) and downregulates Wnt signaling in human cells and zebrafish embryos. PLoS One 8:e67694

38. Drees F, Pokutta S, Yamada S, Nelson WJ, Weis WI (2005) Alpha-catenin is a molecular switch that binds E-cadherin-beta-catenin and regulates actin-filament assembly. Cell 123:903-915

39. Peng X, Cuff LE, Lawton CD, DeMali KA (2010) Vinculin regulates cell-surface E-cadherin expression by binding to beta-catenin. J Cell Sci 123:567-577

40. Kauppi B, Jakob C, Farnegardh M, Yang J, Ahola H, Alarcon M, Calles K, Engstrom O, Harlan J, Muchmore S, Ramqvist AK, Thorell S, Ohman L, Greer J, Gustafsson JA, Carlstedt-Duke J, Carlquist M (2003) The three-dimensional structures of antagonistic and agonistic forms of the glucocorticoid receptor ligand-binding domain: RU-486 induces a transconformation that leads to active antagonism. J 
Biol Chem 278:22748-22754

41. Milhon J, Lee S, Kohli K, Chen D, Hong H, Stallcup MR (1997) Identification of amino acids in the tau 2-region of the mouse glucocorticoid receptor that contribute to hormone binding and transcriptional activation. Mol Endocrinol 11:1795-1805

42. Kucera T, Waltner-Law M, Scott DK, Prasad R, Granner DK (2002) A point mutation of the AF2 transactivation domain of the glucocorticoid receptor disrupts its interaction with steroid receptor coactivator 1. J Biol Chem 277:26098-26102

43. Onate SA, Tsai SY, Tsai MJ, O'Malley BW (1995) Sequence and characterization of a coactivator for the steroid hormone receptor superfamily. Science 270:1354-1357

44. Ding XF, Anderson CM, Ma H, Hong H, Uht RM, Kushner PJ, Stallcup MR (1998) Nuclear receptor-binding sites of coactivators glucocorticoid receptor interacting protein 1 (GRIP1) and steroid receptor coactivator 1 (SRC-1): multiple motifs with different binding specificities. Mol Endocrinol $12: 302-313$

\section{Figure legends}

Fig. 1 GR $\beta$ knock-down impaired the proliferation of U118 and Shg44 glioma cells in vitro and in vivo. a,b A cell growth assay showed growth inhibition in stable GR $\beta$ knock-down U118 glioma cells (siGR $\beta$-U118) and Shg44 glioma cells (siGR $\beta$-Shg44). ${ }^{* *} p<0.01$, vs. Scramble control cells (scGR $\beta$-U118 or scGR $\beta$-Shg44), $n=6$. Insets showed the Western blotting results depicting the effect of GR $\beta$ knockdown. c,d EdU incorporation experiment demonstrated inhibited proliferation in siGR $\beta$-U118 cells and siGR $\beta$-Shg44. The upper panels illustrated the double staining of EdU (Red) and nuclei (Hoechst, blue). Lower panels showed the quantification of EdU positive cells. Data were expressed as the percentage of EdU to Hoechst labeling. ${ }^{*} p<0.05, \mathrm{n}=6$. Scale bar, $50 \mu \mathrm{m}$. e,f GR $\beta$ knock-down resulted in a suppression of colony formation. Cell colonies were counted and plotted. ${ }^{*} p<0.05, \mathrm{n}=4$. $\mathbf{g}$ GR $\beta$ knock-down suppressed the tumor formation in a human glioma xenograft mouse model. Representative images (top) and weight (bottom) of tumors obtained from nude mice injected subcutaneously with U118 or Shg44 stable cells. ${ }^{* *} p<0.01, \mathrm{n}=6$.

Fig. 2 GR $\beta$ knock-down decreased TCF/LEF transcriptional activity in glioma cells. a,b Luciferase reporter assays showed TCF/LEF transcriptional activity in U118 (a) and Shg44 (b) cells after GR $\beta$ knock-down. Luciferase assays were performed in U118 or Shg44 stable cells transfected with an OT/OF-Luc Flash reporter and pRL-TK (as an internal control). Relative luciferase activities were normalized with the internal control. $* * p<0.01, \mathrm{n}=6$. c,d Western blot analysis of Cyclin D1, TCF- 4 and $\beta$-catenin in U118 and Shg44 stable cells. $\beta$-actin served as a loading control. The quantification of relative Cyclin D1 expression was shown in the right panel. ${ }^{* *} p<0.01, \mathrm{n}=3$. e ChIP assay showed decreased binding of TCF-4 to the Cyclin D1 promoter in GR $\beta$ stable knock-down U118 cells. The ChIP DNA samples obtained using anti-TCF-4 antibody, anti-RNA polymerase II antibody (Anti-Poly II) or a normal IgG were subjected to PCR to amplify the Cyclin D1 or GAPDH fragment using specific promoter primers. For input, $1 \%$ of the Non-IP samples were used. The right panel shows the quantification of the relative DNA binding determined using the ratio of anti-TCF-4/Input. ${ }^{*} p<0.05, \mathrm{n}=3$. 
Fig. 3 Cell growth regulation of GR $\beta$ in U118 cell is $\beta$-catenin-TCF complex independently. a Immunoprecipitation (IP) analysis showed no change of TCF-4 and $\beta$-catenin interaction in U118 and Shg44 cells after GR $\beta$ knock-down. Cell proteins were immunoprecipitated with mouse anti-TCF-4 antibody and analyzed by an immunoblot (IB) with rabbit anti-TCF-4 and $\beta$-catenin antibodies. b Triple immunostaining of $\beta$-catenin (Red), GR $\beta$ (Green) and TCF-4 (blue) of normal U118 and Shg44 glioma cells. c IP analysis of TCF-4 and $\beta$-catenin in normal HCT116, U118 and Shg44 cells. d-f Cell growth assay of normal HCT116 (d), U118 cells (e) and Shg44 cells (f) treated with iCRT3 $(25 \mu \mathrm{M})$ or DMSO. ${ }^{* *} p<0.01, \mathrm{n}=6$. g,h Cell growth assay showed a growth inhibition in normal U118 cells (g) and Shg44 cells (h) after a TCF-4 siRNA transfection. ${ }^{* *} p<0.01, \mathrm{n}=6$. Insets showed the RT-PCR results depicting the effect of TCF-4 siRNA transfection.

Fig. 4 GR $\beta$ interacted with TCF-4 directly by binding to its N-terminus. a Double immunostaining of TCF- 4 (green) and GR $\beta$ or GR $\alpha$ (red) in normal U118 cells. GR $\beta$ exhibited a predominantly nuclear distribution and co-localized with TCF-4. GR $\alpha$ was mainly distributed in the cytoplasm and showed minimal co-localization with TCF-4. Hoechst served as a nuclear staining. Bars, $20 \mu \mathrm{m}$. b TCF-4 interacted with GR $\alpha$ and GR $\beta$ in U118 cells. Cell proteins were immunoprecipitated with mouse anti-TCF-4 antibody and analyzed by IB with rabbit anti-TCF-4 and GR $\alpha$ or GR $\beta$ antibodies. The lower panel shows the quantification of relative binding of GR $\alpha$ or GR $\beta$ to TCF -4 . ${ }^{*} p<0.05, \mathrm{n}=3$. c GR $\alpha$ and GR $\beta$ interacted with TCF-4 in a $\beta$-catenin independent manner. MDA-MB-453 cells were transfected with Myc-TCF-4 and pk7-GR $\alpha$-GFP (left panel) or pDsRed1-GR $\beta$ (right panel) plasmids. Cell proteins were immunoprecipitated with mouse anti-Myc antibody and analyzed by IB with rabbit anti-Myc and GFP or RFP antibodies. $\mathbf{d}$ GR $\alpha$ and GR $\beta$ interact with the N-terminal of TCF-4. HEK293 cells were transfected with pDsRed1-GR727 and Myc-TCF-4, Myc-dnTCF-4 or pcDNA-Myc vectors. Cell proteins were immunoprecipitated with mouse anti-RFP antibody and analyzed by IB with rabbit anti-Myc and RFP antibodies.

Fig. 5 GR $\beta$ knock-down, but not GR $\alpha$ reduced TCF/LEF transcriptional activity in GR $\beta$ knock-down stable U118 cells. a No changes of TCF/LEF transcriptional activity were witnessed in GR $\beta$ stable knock-down U118 cells after GR siRNA transfection. Cells were transfected with GR siRNA for 24h followed by a transfection with OT/OF and pRL-TK plasmids. b Western blot analysis of Cyclin D1 expression in GR $\beta$ stable knock-down U118 cells transfected with GR siRNA for $72 \mathrm{~h}$. $\beta$-actin served as a loading control. The lower panel shows the quantification of relative Cyclin D1 expression. c No significant effects of GR knock-down on cell growth in GR $\beta$ stable knock-down U118 cells were observed. d ChIP assay showed increased binding of TCF- 4 to the Cyclin D1 promoter in GR $\beta$ stable knock-down U118 cells after a $72 \mathrm{~h}$ of pDsRed1-GR $\beta$ transfection. The right panel shows the quantification of relative DNA binding. ${ }^{* *} p<0.01, \mathrm{n}=3$. e Western blot analysis of Cyclin D1 expression in GR $\beta$ stable knock-down U118 cells transfected with pDsRed1-GR $\beta$ for $72 \mathrm{~h}$. $\beta$-actin served as a loading control. The lower panel portrays the quantification result. ${ }^{*} p<$ $0.05, \mathrm{n}=3$. 
Fig. 6 The effects of GR $\beta$ on Wnt signaling were dependent on the DBD and LBD. a Schematic view of full length hGR $\alpha, h G R \beta$ and its deletion mutants used in b and c. C-terminal shaded domains in GR $\alpha$ and GR $\beta$ showed their specific portions. $D B D$ DNA-binding domain, $L B D$ Ligand binding domain, $N T D$ N-terminal domain, AF2 Activation functions 2 domain. $\mathbf{b}$ Interaction of TCF-4 and GR $\beta$ or its mutants were analyzed by IP and IB. COS- 1 cells were transfected with Myc-TCF-4 and wtGR $\beta$ or its mutants. Cell proteins were immunoprecipitated with mouse Myc antibody and analyzed by IB with rabbit anti-RFP and Myc antibodies. c Luciferase assay of TCF/LEF transcriptional activity in COS- 1 cells transfected with Myc-TCF- 4 and wtGR $\beta$ or mutants for $48 \mathrm{~h}$ and followed by a transfection of OT/OF-Luc and pRL-TK vectors. Wnt1 $(10 \mathrm{ng} / \mathrm{ml})$ was added $6 \mathrm{~h}$ before assay. ${ }^{* *} p<0.01, \mathrm{n}=3$.

Fig. 7 A working model of the function of GR on TCF/LEF transcriptional activity. In the absence of glucocorticoids (GCs), GR $\alpha$ localizes in the cytoplasm and GR $\beta$ is located in the nucleus. In the nucleus, GR $\beta$ enhances transcription of target genes by direct binding of the GR $\beta$-specific response element (a) or by tethering itself to the TCF/LEF complex upon DNA binding (b). Upton binding GCs, cytoplasmic GR $\alpha$ undergoes an activation process and translocates to the nucleus, where it enhances or represses transcription of target genes by direct GRE binding (data not shown) or by interacting with other transcriptional factors and modulating their transcriptional activity. Ligand-activated GR $\alpha$ may compete with GR $\beta$ to form a heterodimer or homodimer which determines the inhibitory function of GR $\alpha$ on TCF/LEF transcriptional activity (c, d). 
A

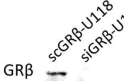
$\beta$-actin $=\beta-\beta$-actin

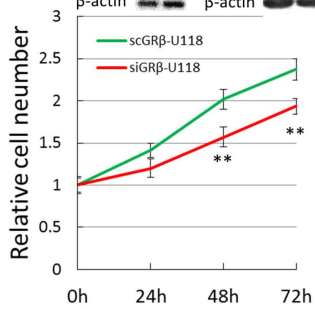

C
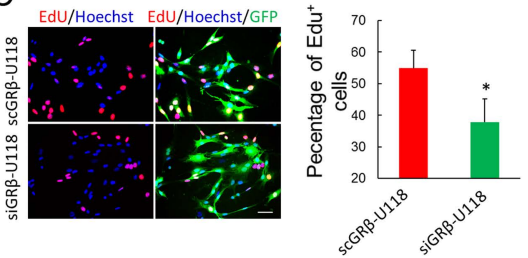

E

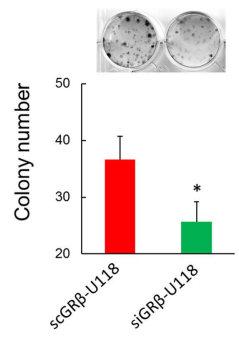

B

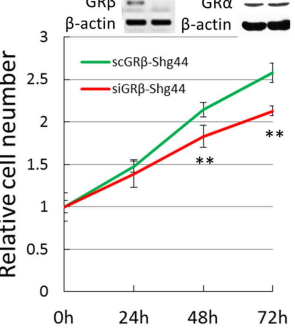

D
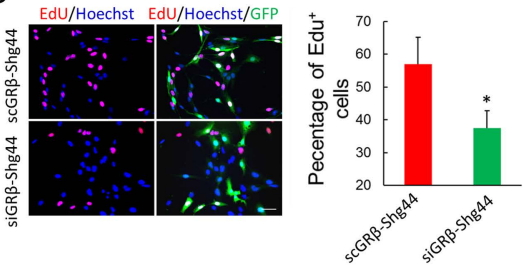

G
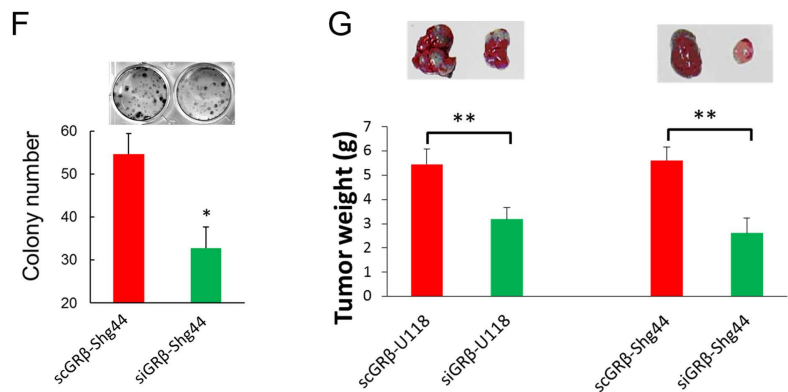
A

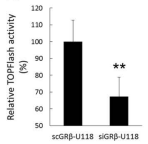

C

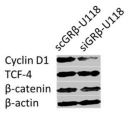

D

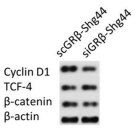

E
Normal IgG

Anti-Poly II

Anti-TCF-4

Input
B
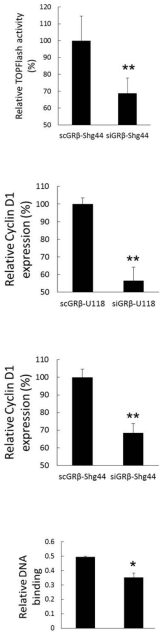

Cyclin D1 
A
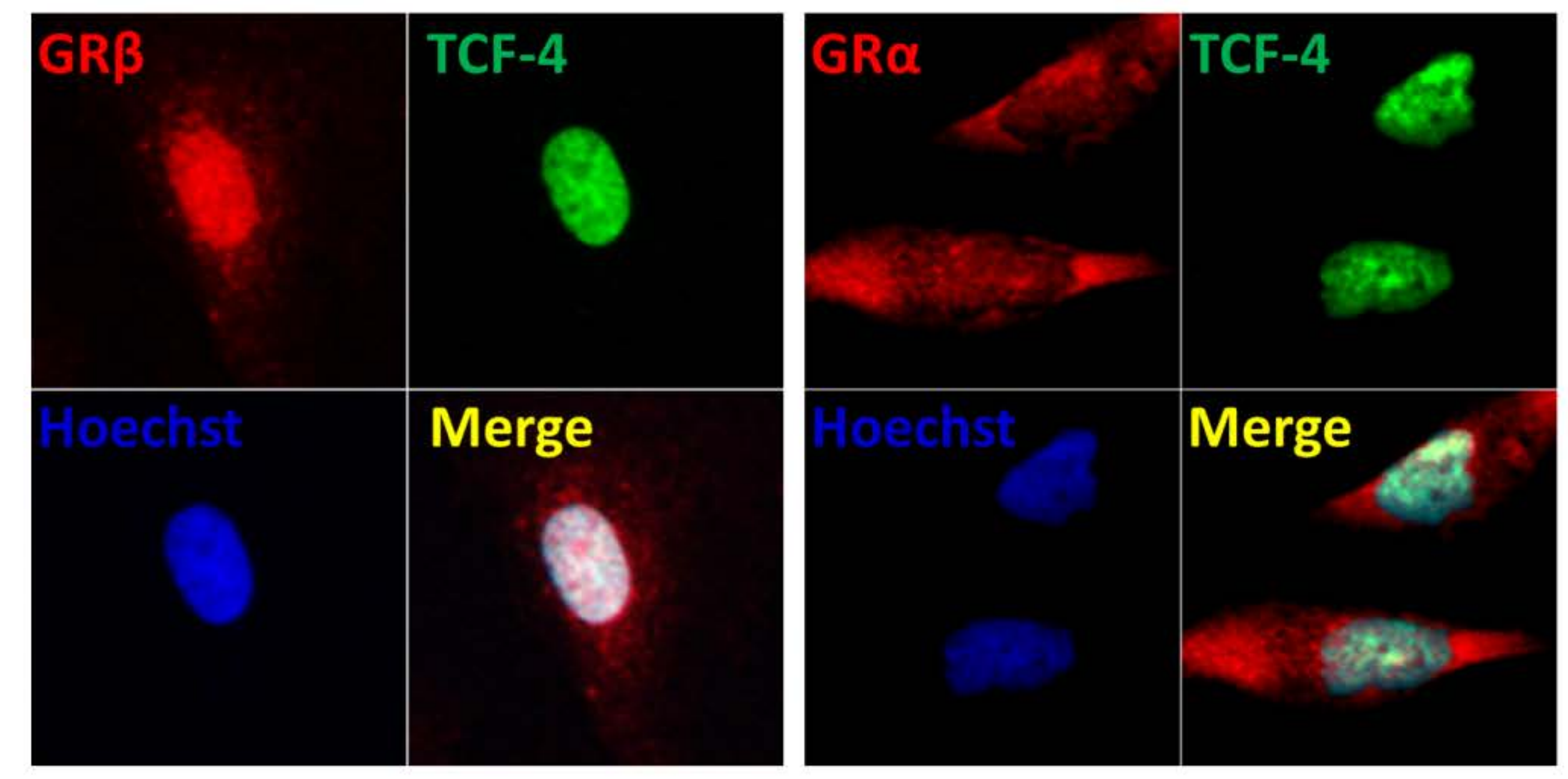

C

IB: GFP $\rightarrow$

IB: Myc $\rightarrow$

IB: GFP

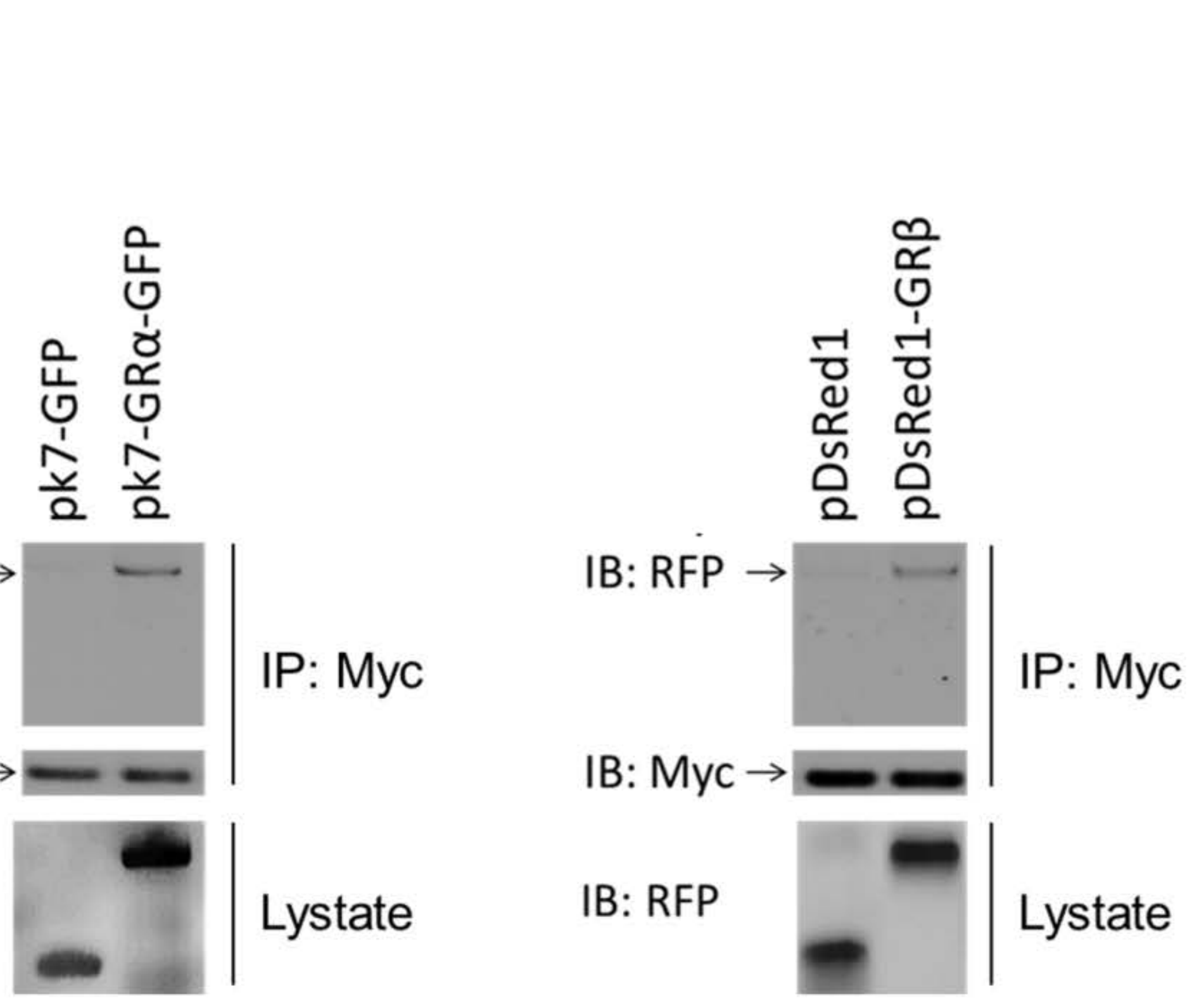

B
IP: TCF4
IP: TCF4
IB: $G R \alpha \rightarrow \cdots$
IB: GR $\beta \rightarrow$
IB: TCF4 $\rightarrow$
IB: TCF4 $\rightarrow$

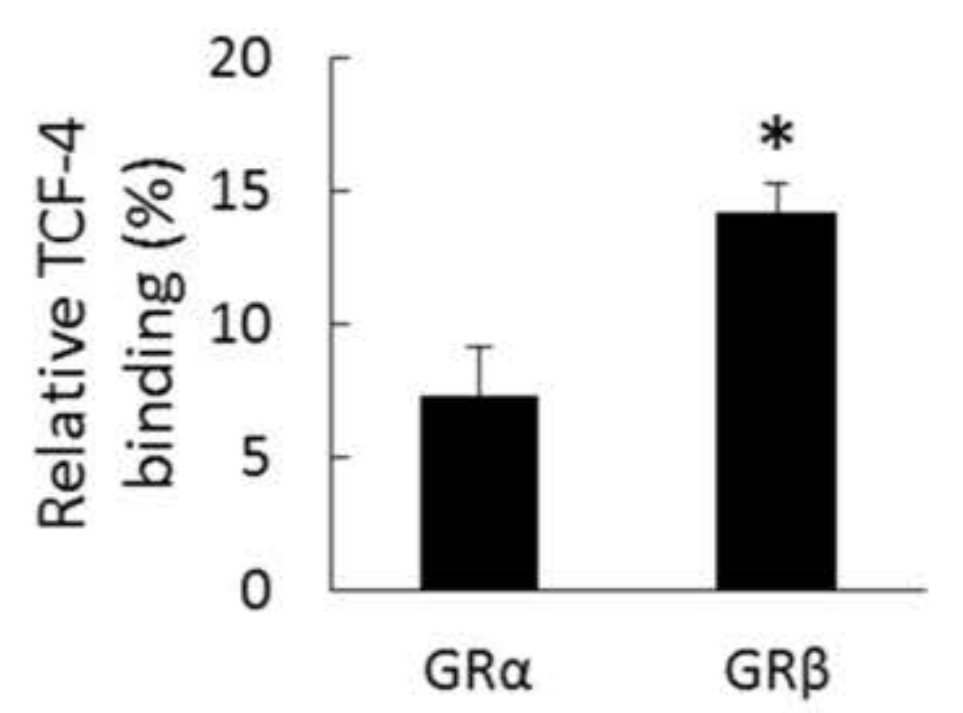

D

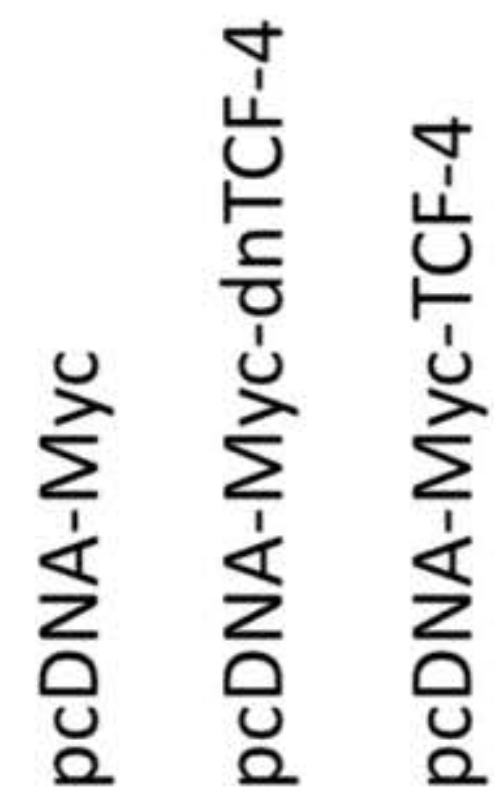

IB: Myc

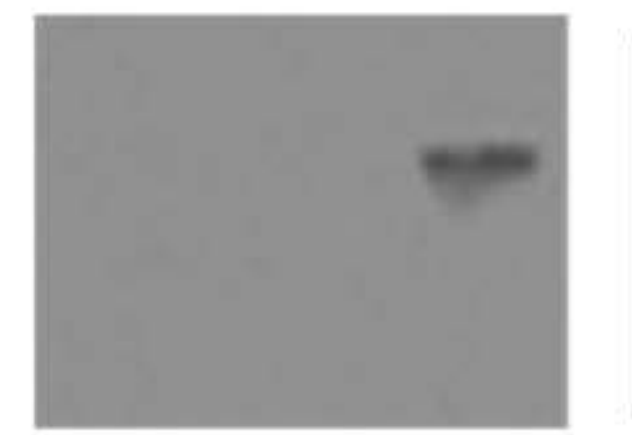

IP: RFP

IB: Myc

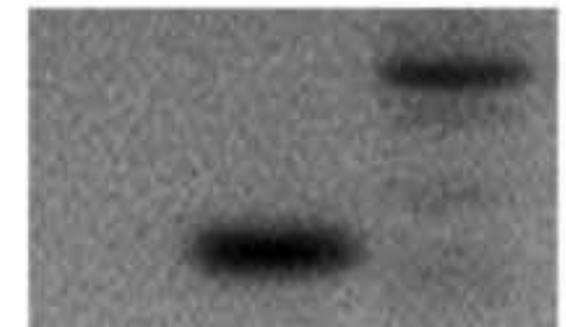

Lystate 
A

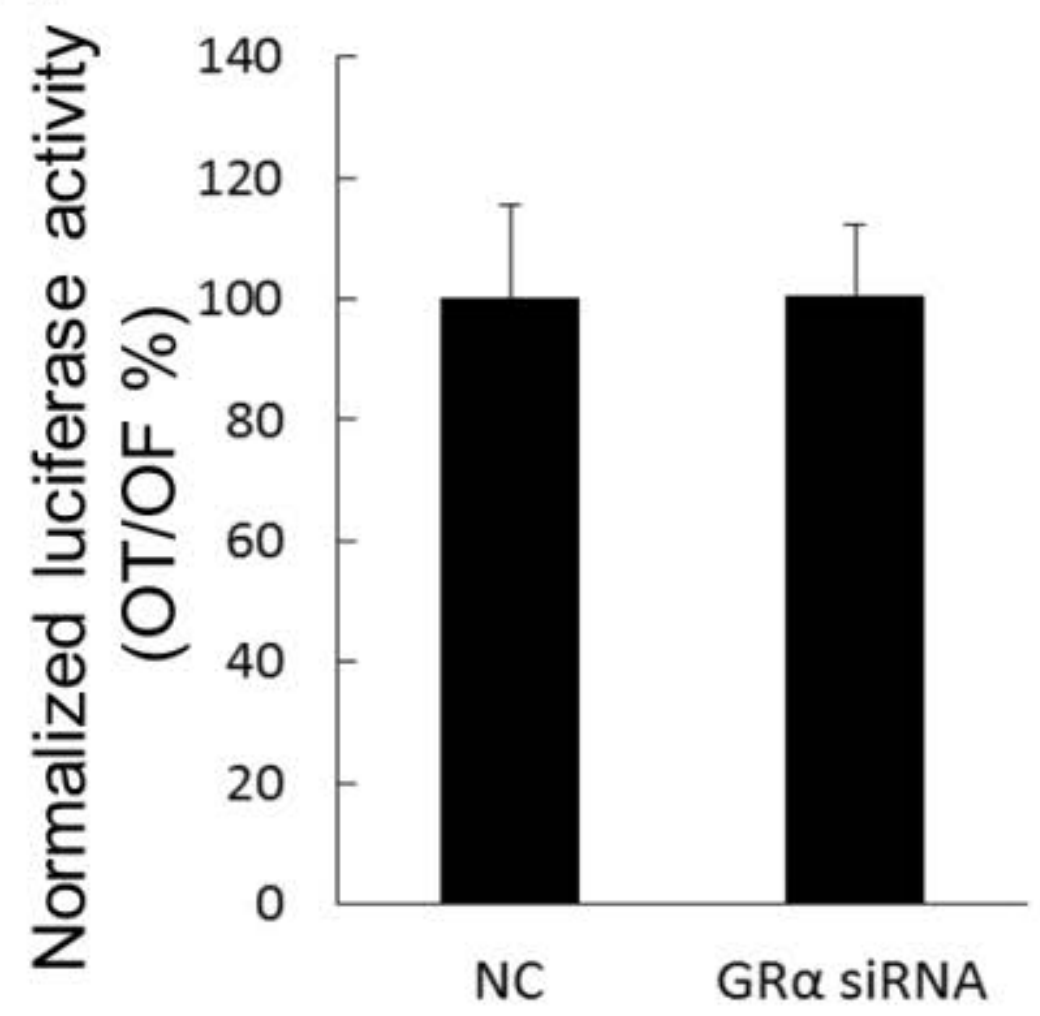

D

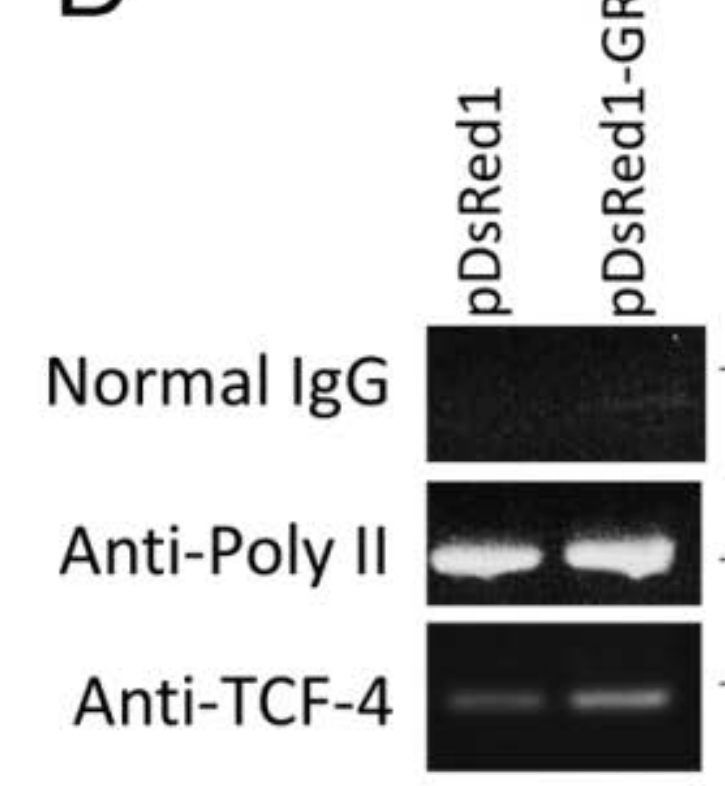

Input
B
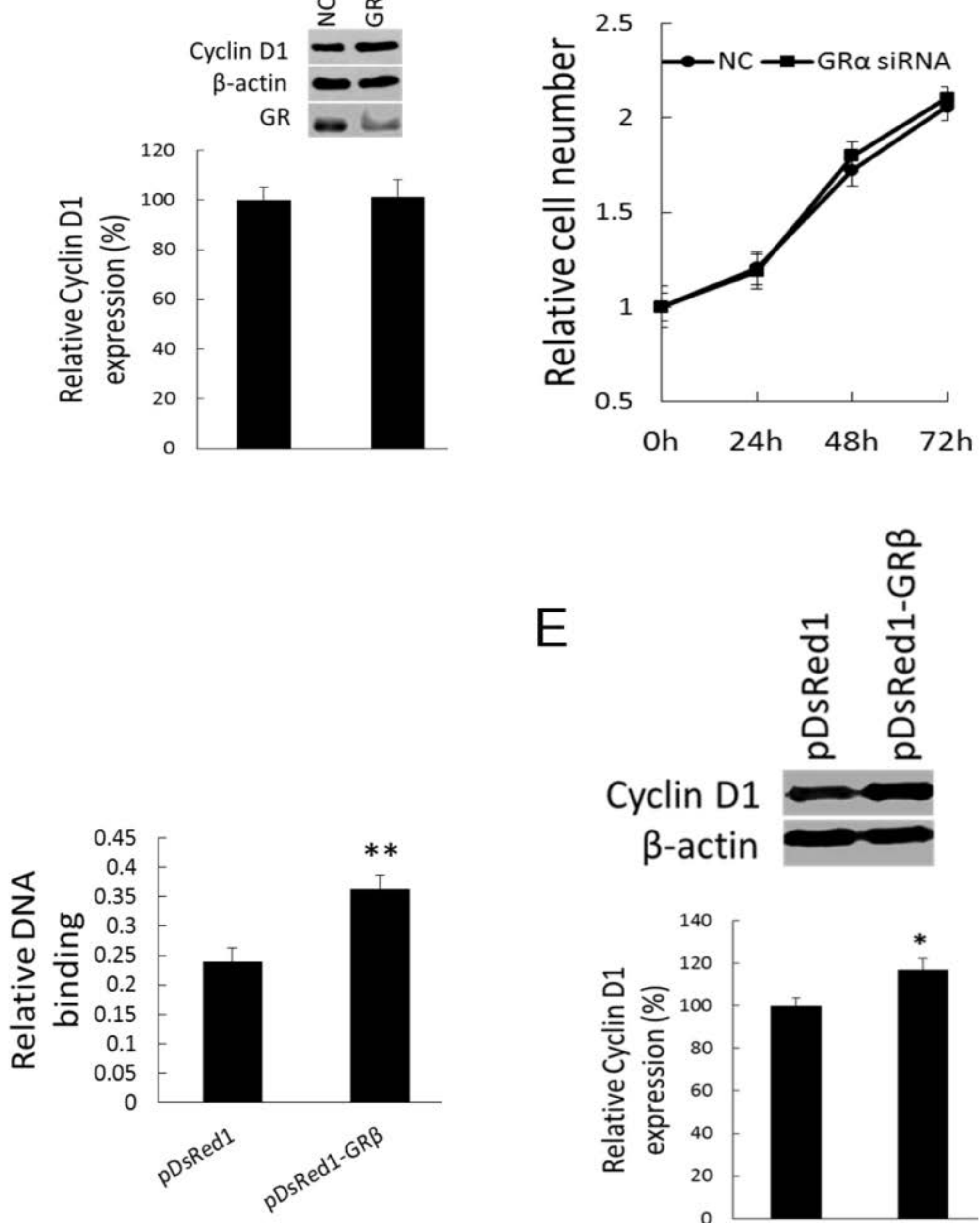

E

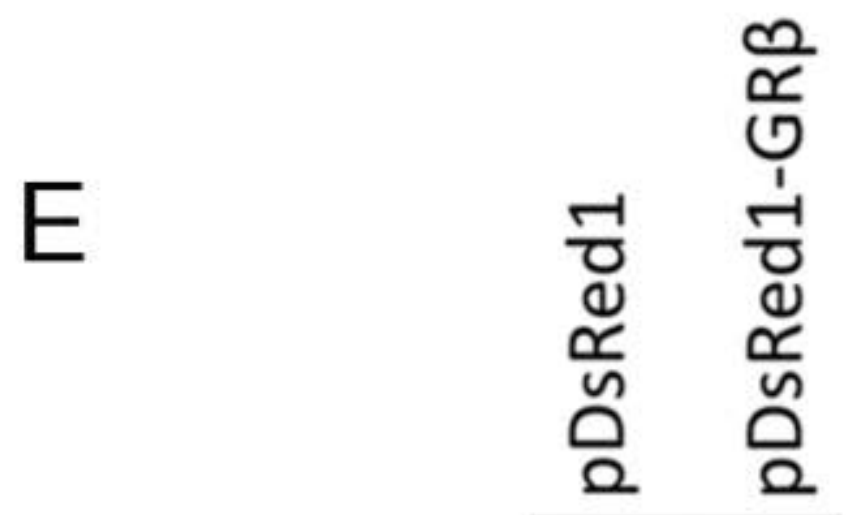

Cyclin D1 $\beta$-actin

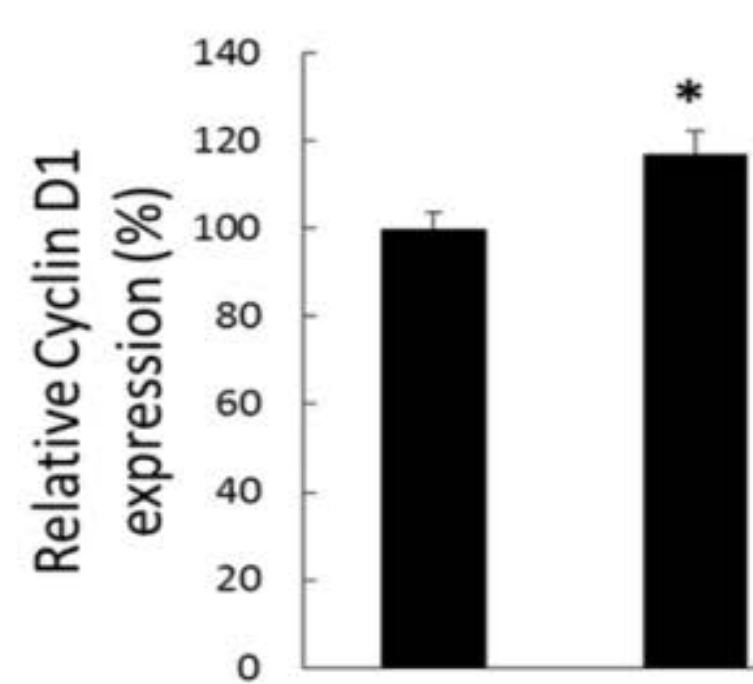


A

hGR $\alpha$

hGR $\beta$

GRß 1-556

GRß 418-742

GRß 418-556

GRß 1-488^556-742

GRß 1-418^488-742

B

IB: RFP

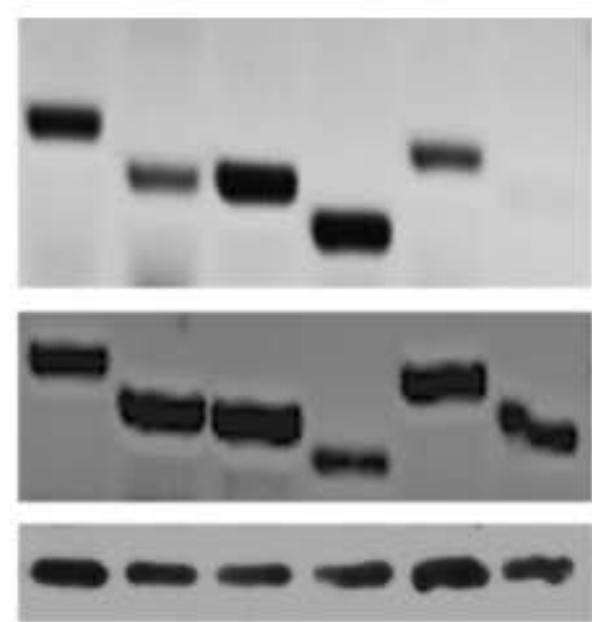

Lystate

IB: Myc

Myc-TCF- $4+++++$

WtGR $\beta$

GR $\beta$ 1-556

GRß 418-742

GRß 418-556

GRß 1-488^556-742

GRß 1-418^488-742
AF2 (753-768)

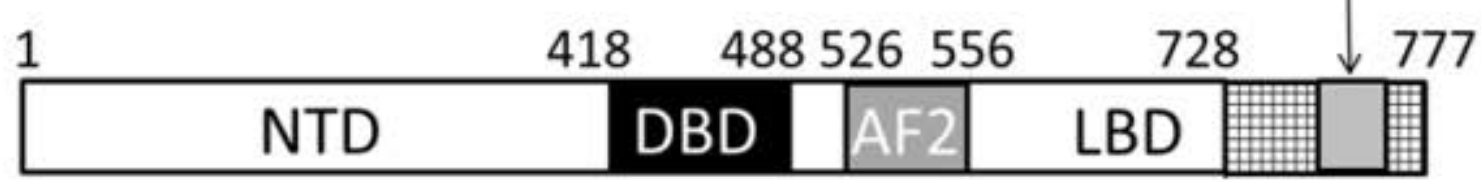

\begin{tabular}{|ll|l|l|l|l}
\hline & 418 & 488526 & 556 & 728 & 742 \\
\hline NTD & DBD & AF2 & LBD VRA
\end{tabular}

DBD $\quad$ AF2

DBD $\triangle A F 2$ LBD

\begin{tabular}{l|l|l|} 
DBD & AF2 \\
\hline
\end{tabular}

\begin{tabular}{|l|l|l|}
\hline NTD & DBD ---- LBD VR \\
\hline
\end{tabular}

\begin{tabular}{|l|l|l|l|l|l|}
\hline NTD & LBD VR \\
\hline
\end{tabular}

C

IP: Myc

Lystate
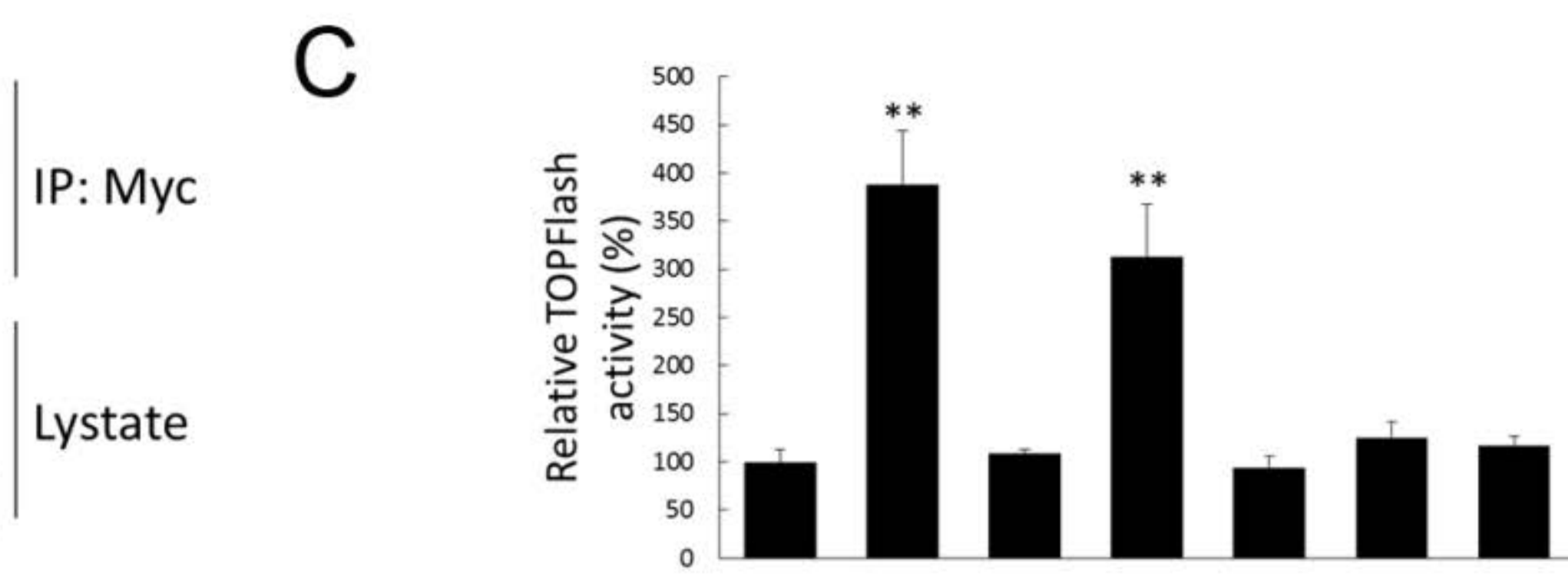

$$
\begin{array}{r}
\text { Myc-TCF-4 } \\
\text { WtGR } \beta \\
\text { GR } \beta 1-556 \\
\text { GRß 418-742 } \\
\text { GR } 418-556
\end{array}
$$

GRß 1-488^556-742

GRß 1-418^488-742 


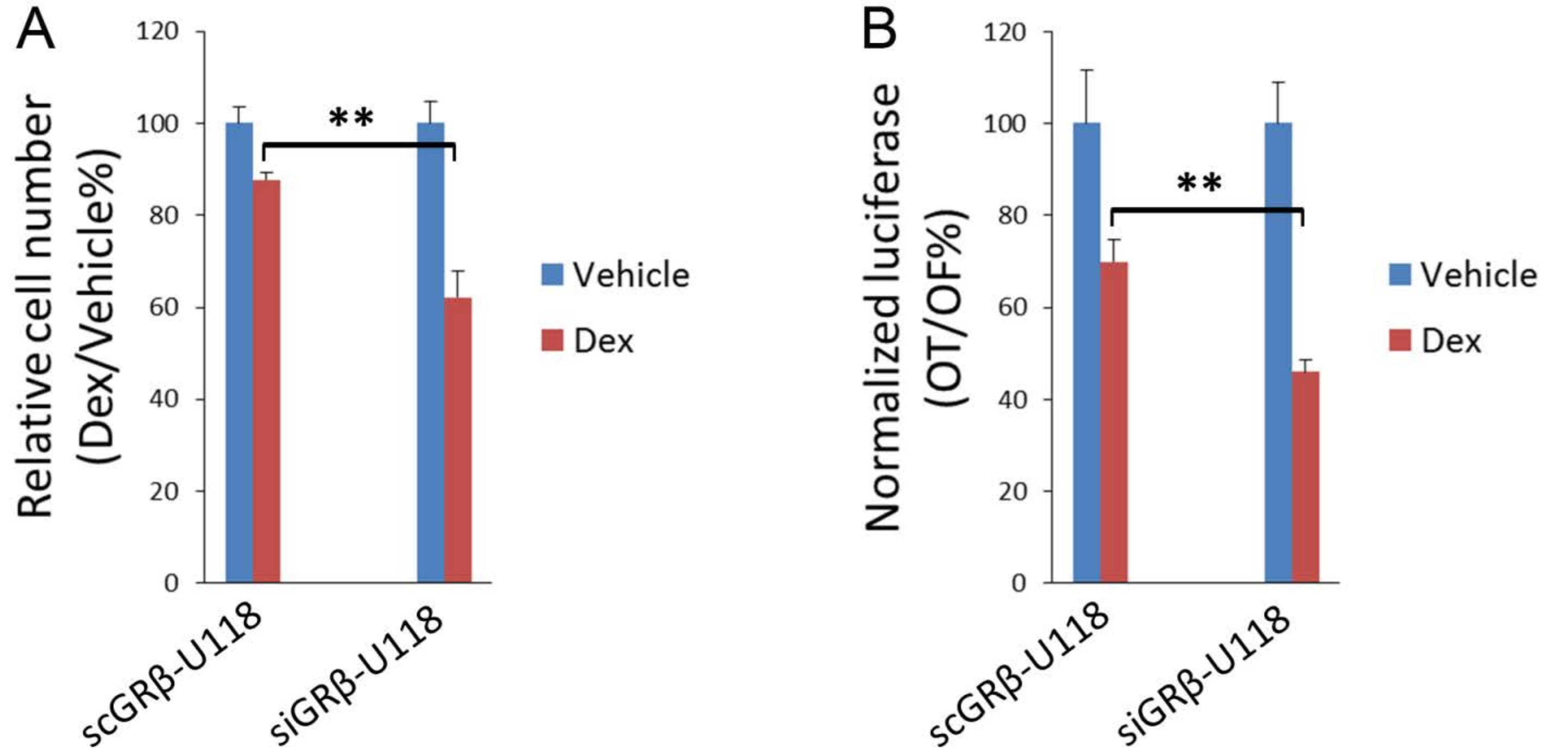


A

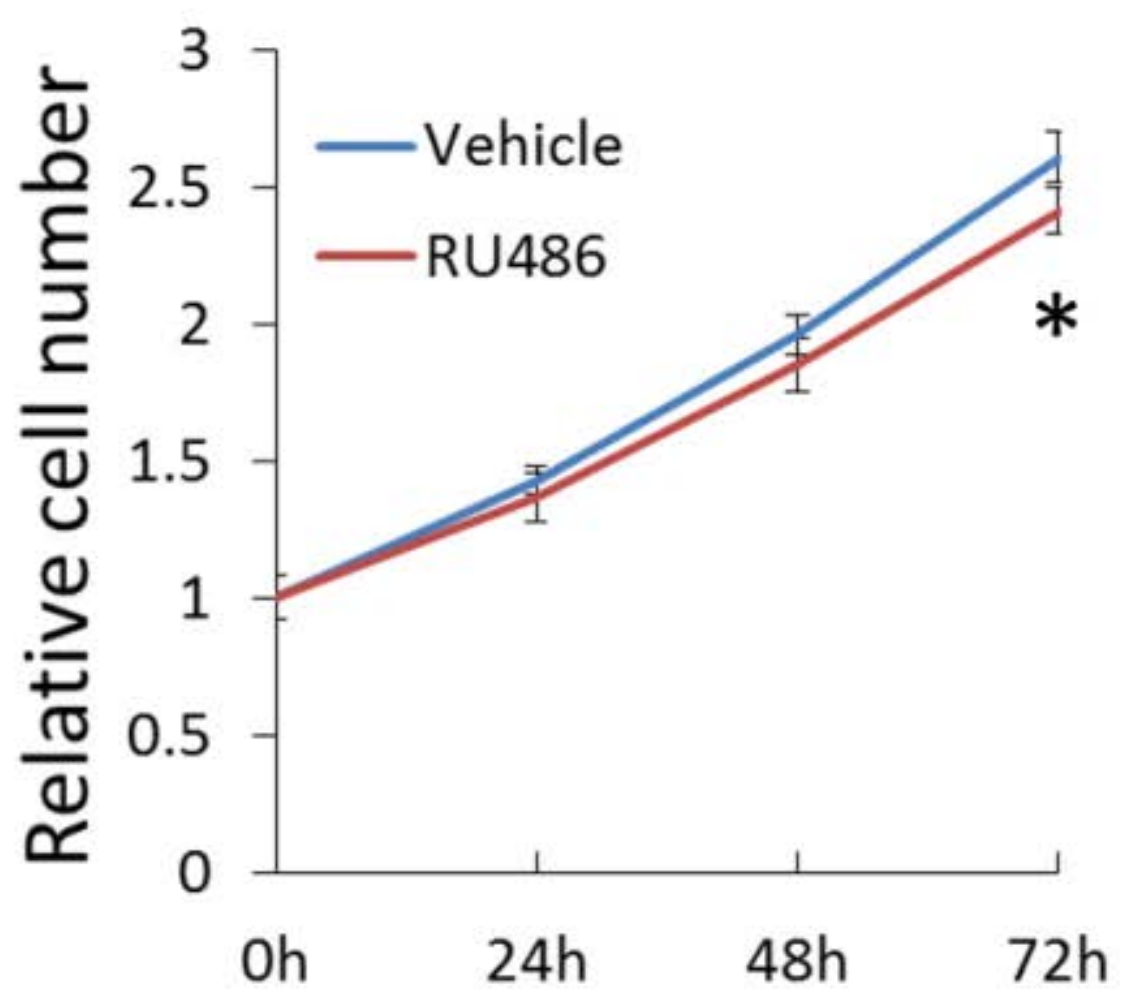

C

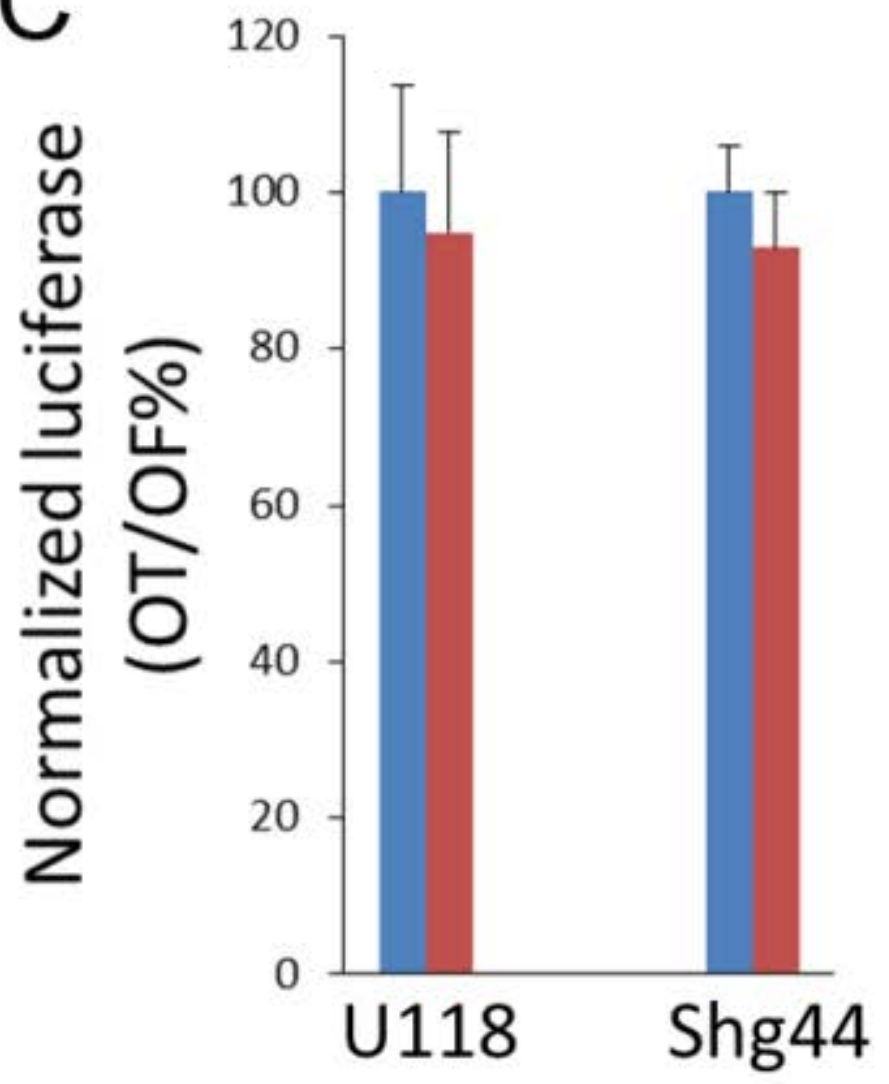

B

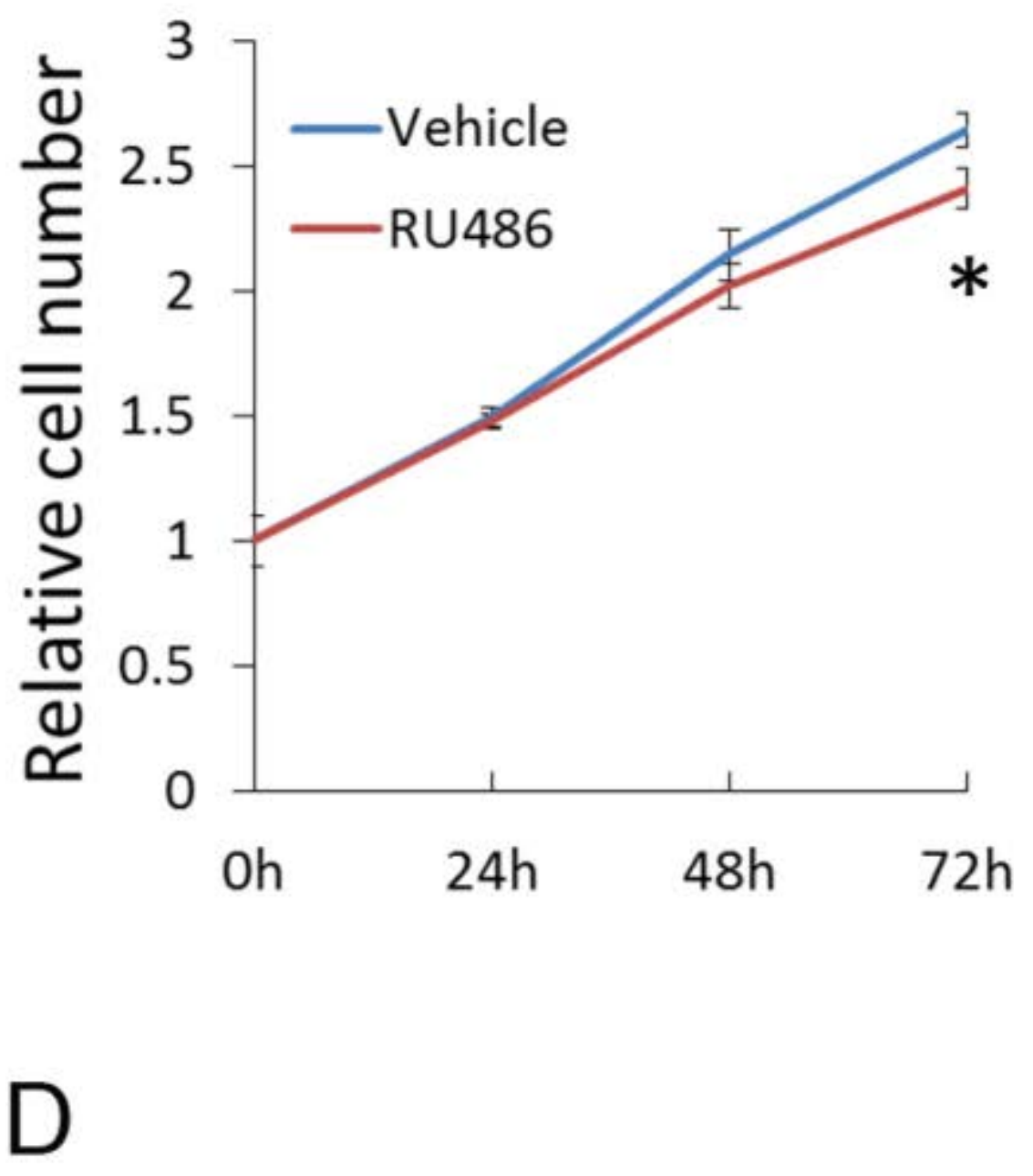

$$
\text { RU486 } \frac{\text { U118 }}{-+}+\frac{\text { Shg44 }}{-+}
$$

IB: GR $\beta$

- Vehicle

nU486
IP: TCF-4

IB: TCF-4

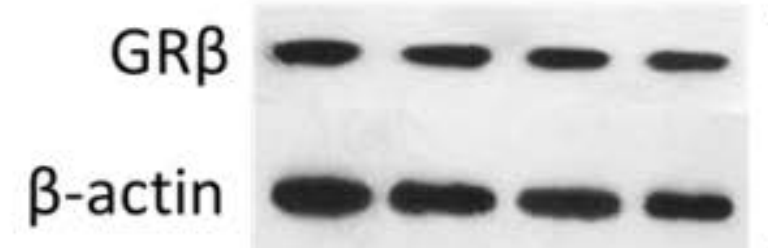

Lystate 
A

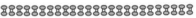
Cytoplasm

Cora

GRe

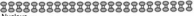
Nuelenas

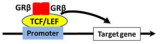

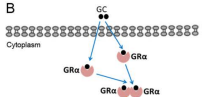

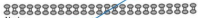
Nucleus

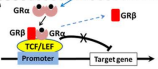

C GC

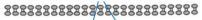
cyeoplasm

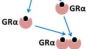

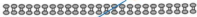
Nuclous

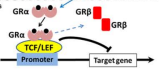

